\title{
The degree functions of negative adjectives
}

\author{
Galit Weidman Sassoon
}

Published online: 6 May 2010

(C) The Author(s) 2010. This article is published with open access at Springerlink.com

\begin{abstract}
This paper provides a new account of positive versus negative antonyms. The data includes well-known linguistic generalizations regarding negative adjectives, such as their incompatibility with measure phrases (cf. two meters tall/ *short) and ratio phrases (twice as tall/ \#short) as well as the impossibility of truly crosspolar comparisons (*Dan is taller than Sam is short). These generalizations admit a variety of exceptions, e.g., positive adjectives that do not license measure phrases (cf. \#two degrees warm/cold) and rarely also negative adjectives that do (cf. two hours late/early). Furthermore, new corpus data is presented regarding the use of twice with positive and negative adjectives. The analysis the paper presents supposes that grammar associates gradable adjectives with measure functions-mapping of entities to a set of degrees isomorphic to the real numbers (Kennedy, Projecting the
\end{abstract}

This paper is based on my dissertation (Sassoon 2007, Chap. 9) and extends a short paper from the proceedings of SALT 18 (Sassoon 2009). My work was made possible by the Orgler Scholarship for excellent PhD students in the humanities, Tel Aviv University (2004-2007) and the Pratt postdoc scholarship, Ben Gurion University of the Negev (2007-2008). Part of the research for this paper was carried out in the project 'On vagueness - and how to be precise enough', funded by the Netherlands Organization for Scientific Research (NWO 360-20-201). I warmly thank Nirit Kadmon, Fred Landman, Robert van Rooij, Frank Veltman, and the audiences of SALT 18, Amherst, the conference 'Vagueness and Language Use', Paris, and the linguistic colloquiums of Jerusalem, Bar-Ilan, and Bee'r-Sheva for their most helpful comments. Special thanks to Arik Cohen, Nomi Shir, Idan Landau, Dorit Ben-Shalom, Lavi Wolf, Rachel Giora, Roger Schwarzschild, Irene Heim, Chris Kennedy, Louise McNally, Yael Sharvit, Jonathan Bobaljik, Gabi Danon, Jonathan Fine, Susan Rothstein, Yael Greenberg, Idit Doron, Anita Mittwoch, Ivy Sichel, Micha Breakstone, and Adar Weidman.

G. W. Sassoon $(\bowtie)$

ILLC, University of Amsterdam, Science Park 904, Room C3-136K,

1098 XH, Amsterdam, The Netherlands

e-mail: galitadar@gmail.com; adar69@012.net.il

G. W. Sassoon

Haverstede 19, 1112 HR, Diemen, The Netherlands 
adjective: The syntax and semantics of gradability and comparison, 1999). On this analysis, negative adjectives map entities to values that are linearly reversed and linearly transformed in comparison with their values in the positive antonyms. As shown, the generalizations, as well as their exceptions, directly follow. Negative polarity is explained in terms of function reversal, and non-licensing of measure phrases is explained in terms of transformation by an unspecified value.

Keywords Negative adjective - Transformation - Degree $\cdot$ Measure · Comparison · Ratio modifiers

\section{Introduction}

Existing accounts of 'positive' and 'negative' antonyms often treat the concepts of antonymy and polarity as primitive (Lehrer and Lehrer 1982), or else they provide criteria to distinguish between positive and negative antonyms, but these criteria typically have exceptions. Despite it being notoriously difficult to define the set of negative as opposed to positive adjectives, it is clear that there is a phenomenon underlying this intuitive distinction, as illustrated shortly. Hence, Sects. 2-4 of this paper focus on paradigmatic antonym pairs, such as long-short, tall-short, deepshallow, wide-narrow, and old-young. Discussion of additional data and analyses pertaining to non-paradigmatic pairs (such as warm-cold, heavy-light, expensiveinexpensive, rich-poor, late-early, and fast-slow) is delayed to Sect. 5.

Section 2 describes well-known (but, to my mind, still puzzling) linguistic contrasts between positive and negative adjectives in paradigmatic antonym pairs. As some contrasts pertain to the licensing of numerical degree phrases, this paper presupposes that grammar encompasses a set of degrees identical or isomorphic to the set of real numbers, $\Re$ (Kennedy 1999, 2001; Fox and Hackl 2006; Fox 2007; Nouwen 2008). Gradable adjectives map entities to such degrees. Yet, this paper rejects the standard assumption that the mapping is generally additive (in the sense defined in Sect. 3; cf. Klein 1991). A new analysis is presented according to which adjectives are 'negative' iff they are predominantly associated with linearly reversed and transformed mapping functions (cf. the definitions in (14) and (51) below). Section 4 shows in detail that the facts regarding paradigmatic antonym pairs follow directly from this analysis. Section 5 focuses on a broader set of antonym pairs, showing that many are characterized differently than the paradigmatic pairs discussed earlier. Still, the proposed analysis nicely captures the facts. In addition to grammaticality judgments, novel findings are presented, based on a corpus study of uses of the ratio modifier twice in equative constructions (i.e., constructions of the form 'as Adj. as') with positive and negative antonyms. The paper concludes with a brief comparison of the analysis with existing accounts.

When one looks at a broad set of antonym pairs, the data is far from 'clean'. We need a theory that is flexible enough to accommodate this situation, while still producing clear-cut predictions regarding paradigmatic cases and regarding the connections between the different tests for the polarity of adjectives. I hope to show that my theory does precisely that. 


\section{Paradigmatic positive and negative antonyms}

Gradable adjectives impose orderings on the entities under discussion. Intuitively, the entity orderings imposed by negative adjectives, like short, are reversed in comparison with those of their positive antonyms, e.g., tall, as statements like (1) demonstrate.

\section{(1) Dan is taller than Sam iff Sam is shorter than Dan.}

Furthermore, the reversal triggered by the use of negative antonyms is linear in the sense that it preserves the differences between entities, as the intuitive judgments in (2) demonstrate.

(2) a. Dan is two inches taller than Sam iff Sam is two inches shorter than Dan.

b. Dan is two inches shorter than Sam, who is two inches shorter than Bill iff Dan is four inches shorter than Bill.

The ontology underlying these intuitions can be described as follows. The adjectives in a paradigmatic antonym pair are associated with a common measure, e.g., a measure of heights. Let us call this measure the base function. While positive adjectives associate directly with their base functions, their negative antonyms are linearly reversed in comparison with them, e.g. tall assigns higher values to entities with bigger heights, whereas short assigns higher values to entities with smaller heights; old assigns higher values to entities with more age, whereas young assigns higher values to entities with less age, etc. Nonetheless, the differences between entities' values in positive and negative antonyms are identical (cf. (2a)).

One could argue that adjectives like short and young are neither special nor negative in any sense at all. Rather, they too (like tall and old) are interpreted as 'non-reversed' in comparison with measures of 'shortness' and 'youth', respectively. But 'shortness' and 'youth' are themselves 'reversed' height and age measures. Thus, the notion of linear reversal resists this objection. Furthermore, as illustrated below, a number of systematic linguistic differences exist between these adjectives and their antonyms. These would be unexpected if these adjectives weren't special ('negative').

Consider two birds, an ostrich and a chicken. The height of the former, sixty inches, is twice the height of the latter. First, we can felicitously say that the ostrich is sixty inches tall, but we cannot felicitously say that the chicken is thirty inches short. Generally speaking, while some positive adjectives license numerical degree modifiers ('measure phrases' like sixty inches), negative adjectives virtually never do. Then again, we could say both that the ostrich is thirty inches taller than the chicken and that the chicken is thirty inches shorter than the ostrich. Thus, in the comparative, both positive and negative adjectives license numerical degree modifiers (Horn 1972; Seuren 1978, 1984; von Stechow 1984b; Bierwisch 1989; Kennedy 2001).

Second, cross-polar comparisons like The ostrich is taller than the chicken is short are infelicitous (Kennedy 1999, 2001). The inverse cross-polar comparison, 
i.e., The chicken is shorter than the ostrich is tall, is rather odd too, but it is marginally accepted when there is no emphatic stress on tall (Landman 2005). However, when tall is replaced by a different antonym, as in The ladder is shorter than the house is high, or than the gap is wide, the result is perfectly acceptable (Büring 2007). Generally, we prefer cross-polar comparisons with the negative adjective in the matrix clause to comparisons with it in the than-clause (as in *The gap is wider than the ladder is short).

Third, though it is perfectly acceptable to say that the ostrich is twice as tall as the chicken, to say that the chicken is twice as short is awkward (Horn 1972; Seuren 1978, 1984; von Stechow 1984b; Bierwisch 1989; Kennedy 2001). In general, the use of ratio statements with negative adjectives is not completely ruled out. Yet, these statements are significantly less felicitous than ratio statements with the corresponding positive antonyms, as the following felicity contrasts demonstrate.

(3) a. The table is twice as tall/long/big/wide as the sofa.

b. \#The table is twice as short/small/narrow as the sofa.

(4) a. This swimming pool is twice as deep as that one.

b. \#This swimming pool is twice as shallow as that one.

Furthermore, ratio statements with negative adjectives are significantly less common, and their use seems to be restricted to non-default interpretations of negative adjectives (cf. Sect. 5.4).

Finally, classification by cultural conventions is irrelevant, e.g., whether being old is regarded as more positive than being young or not is orthogonal to the distinction we are after. Linguistically, old is positive and young is negative; thus it is old that combines with numerical degree modifiers, such as two years, also in its positive (non-comparative) form (Kennedy 1999; Svenonious and Kennedy 2006). The next part of this paper presents a semantic analysis that accounts for the linguistic contrasts between positive and negative antonyms, not for cultural facts.

\section{A new proposal: linear function reversal and transformation}

\subsection{Basic assumptions}

To set the stage, Sect. 3.1 presents some background assumptions regarding partial information and gradability.

Following Stalnaker (1978), let us call the linguistic and world knowledge of a given community of speakers an actual context. The interpretation of linguistic expressions in contexts $\mathrm{c}$ is typically modeled via a set of indices $\mathrm{T}_{\mathrm{c}}$ - the worlds (Stalnaker 1978) or completions (van Fraassen 1969; Kamp 1975; Fine 1975; Veltman 1984; Landman 1991) consistent with the information in c (completions being 'classical' contexts, wherein every statement is either true or false). The truth of a statement $\varphi$ in $\mathrm{c}$ is defined based on these indices: 

a. $\llbracket \varphi \rrbracket_{\mathrm{c}}=1$ iff $\forall \mathrm{t} \in \mathrm{T}_{\mathrm{c}}, \llbracket \varphi \rrbracket_{\mathrm{t}}=1$
b. $\llbracket \varphi \rrbracket_{\mathrm{c}}=0$ iff $\forall \mathrm{t} \in \mathrm{T}_{\mathrm{c}}, \llbracket \varphi \rrbracket_{\mathrm{t}}=0$
c. Otherwise, $\llbracket \varphi \rrbracket_{\mathrm{c}}$ is undetermined.

For example, the truth of a statement like It rains is considered common knowledge in a given context $\mathrm{c}$ iff it holds true in every completion $\mathrm{t}$ in $\mathrm{T}_{\mathrm{c}}$; the falsity of a statement is considered common knowledge in c iff it is false (it does not rain) in every completion $\mathrm{t}$ in $\mathrm{T}_{\mathrm{c}}$. The truth value is undetermined in $\mathrm{c}$ iff $\mathrm{T}_{\mathrm{c}}$ includes both a completion in which it is true (it rains) and a completion in which it is false (it does not rain).

Semanticists often characterize gradable adjectives as mapping entities x (elements of the domain of discourse $\mathrm{D}_{\mathrm{x}}$ ) to degrees. For example, the adjective tall maps entities to degrees representing their heights. There is much controversy as to the nature of these degrees (for a review see Klein 1991). According to one view, degrees are elements of a linearly ordered set isomorphic to the real numbers, $\Re .^{1}$ It may well turn out that, for example, rather than actual numbers, different extents of brain activation and suppression underlie the notion of degrees. However, treating degrees as actual numbers is most useful in demonstrating notions such as additivity and its lack thereof, degree differences, degree ratios, etc. What is more, the identification of degrees with numbers does not imply that speakers consciously possess the concept 'real number' any more than they possess concepts like 'lambda' (assuming the latter are part of grammar). Thus, this paper represents degrees straightforwardly numerically. The number ' 5 ', for example, can represent a quantity of apples. In the same way, '5' can also represent a given amount of water, happiness, or height, these seen as entities in the domain $\mathrm{D}_{\mathrm{x}}$ (even if abstract ones).

This paper assumes a $\lambda$-categorial language in the style of Heim and Kratzer (1998), with basic types $\mathrm{x}$ for individuals, $\mathrm{t}$ for truth values, and $\mathrm{r}$ for numerical degrees, and basic semantic domains $\mathrm{D}_{\mathrm{x}}, \mathrm{D}_{\mathrm{t}}$, and $\mathrm{D}_{\mathrm{r}}=\Re$ (sets of individuals, truth values, and numerical degrees, respectively). Gradable adjectives are interpreted as follows:

(6) For any context $\mathrm{c}$, for any $\mathrm{t} \in \mathrm{T}_{\mathrm{c}}$ and any gradable adjective $\mathrm{P}$ :

a. Let $\mathrm{f}_{\mathrm{P}, \mathrm{t}} \in \Re^{\mathrm{Dx}}$ be the degree function of $P$ in $t$ (a function from entities $\mathrm{x}$ in the domain $\mathrm{D}_{\mathrm{x}}$ to real numbers $\mathrm{r}$ in $\Re$ )

b. P holds true of an object $\mathrm{x} \in \mathrm{D}_{\mathrm{x}}$ in $\mathrm{t}$ iff $\mathrm{x}$ 's value exceeds P's cutoff point: $f_{P, t}(x)>$ cutoff(P,t) (Kennedy 1999).

Furthermore, semantic theories often postulate that adjectives' degree functions are additive with respect to their dimension (the 'stuff', so to speak, they measure). For instance, the degree function of tall is additive with respect to height in that its values represent differences and ratios between entities' heights (Klein 1991). Thus equally tall entities $\mathrm{x}_{1}$ and $\mathrm{x}_{2}$ are mapped to the same number (e.g., 5), and their

\footnotetext{
${ }^{1}$ Cf. Bartsch and Venneman (1971), Kennedy (1999, 2001), Kennedy and McNally (2005), Winter (2005), and Landman (2005); for recent work independently motivating dense scales see Fox and Hackl (2006); Fox (2007), and Nouwen (2008).
} 
concatenation (placing end to end) $\mathrm{x}_{1} \oplus_{\text {height }} \mathrm{x}_{2}$ is mapped to twice that number (e.g., 10). Formally:

(7) A degree function $\mathrm{f}$ is additive with respect to a dimension $\mathrm{Q}$ iff $\forall \mathrm{x}_{1}, \mathrm{x}_{2} \in \mathrm{D}: \mathrm{f}\left(\mathrm{x}_{1} \oplus_{\mathrm{Q}} \mathrm{x}_{2}\right)=\mathrm{f}\left(\mathrm{x}_{1}\right)+\mathrm{f}\left(\mathrm{x}_{2}\right)$ (Klein 1991).

However, many functions are additive with respect to height. We have seen that the mapping of two equally tall entities, $\mathrm{x}_{1}$ and $\mathrm{x}_{2}$, and their concatenation, $\mathrm{x}_{1} \oplus_{\text {height }} \mathrm{x}_{2}$, to the values 5,5 and 10 , respectively conforms to the additivity constraint. But so does their mapping to 2, 2, and 4, respectively, and their mapping to 100, 100, and 200, respectively, etc. Each mapping corresponds to the outcome of measuring heights with some possible ruler (inch, meter, etc.) The absence of a unique additive mapping convention is represented by associating tall with different functions in different indices (completions t of a context c).

Finally, we have intuitions about specific entity values only in the zero case: conventional additive height measures (meter rulers, inch rulers, etc.) always assign the value ' 0 ' to surfaces (Krantz et al. 1971). But they differ in the values they assign to entities possessing height. However, being additive, they all share the same degree ratios. For example, since the height of $\mathrm{x}_{1} \oplus_{\text {height }} \mathrm{x}_{2}$ is twice the height of $x_{1}$, the ratio between their degrees is the number 2 in all the examples just given $(\mathbf{2} \times 5=10 ; 2 \times 2=4 \text { and } 2 \times 100=200)^{2,3}$

$$
\forall \mathrm{x}_{1}, \mathrm{x}_{2} \in \mathrm{D}_{\mathrm{x}}, \exists \mathrm{r} \in \Re: \forall \mathrm{t} \in \mathrm{T}_{\mathrm{c}}, \mathrm{f}_{\mathrm{tall}, \mathrm{t}}\left(\mathrm{x}_{1}\right) / \mathrm{f}_{\mathrm{tall}, \mathrm{t}}\left(\mathrm{x}_{2}\right)=\mathrm{r}
$$

To summarize, this section sets up the following background:

(i) A context-set representation of partial information

(ii) A 'numerical' approach to gradability

(iii) Additivity, at least for paradigmatic positive adjectives like, e.g., tall:

1. Entities with no height are mapped to ' 0 ' in every index (completion);

2. other entities are mapped to an undetermined (index-dependent) number; but

3. the ratio between two entities' height-values is a given index-invariant number.

What about the degree functions of negative adjectives like short? Semanticists often assume that the values they assign to entities depend on the quantities of height possessed by the entities (Rullmann 1995; Landman 2005) or not possessed

\footnotetext{
${ }^{2}$ Additive height functions must map all and only entities with no height to zero, for otherwise they would fail to represent height ratios. Example (11) below demonstrates this.

3 In particular, for any entity $\mathrm{x}$, an index-invariant number represents the ratio between $\mathrm{f}_{\text {tall, } \mathrm{t}}$ of $\mathrm{x}$ and $\mathrm{f}_{\text {tall,t }}$ of a meter unit-object in every t. So the mapping of entities to numbers per a unit like meter is 'conventional' in that it systematically and unambiguously determines a value for any entity in any context c (cf. the analysis of unit names in Sect. 4).
} 
by the entities (Seuren 1978, 1984; von Stechow 1984a; Kennedy 1999, 2001; Schwarzschild 2005). But is the mapping of entities to degrees in negative adjectives like short additive with respect to these quantities? The next section argues that it is not, based on the kinds of intuitions we do or do not have about the degrees assigned by negative adjectives.

\subsection{Negative adjectives and transformation values}

Recall that we have a very strong intuition that the degree function of short is linearly reversed in comparison with that of tall (cf. Sect. 2). Differences between values of entity pairs are identical in a positive adjective and its negative antonym (e.g., for any $\mathrm{x}, \mathrm{y}$ in $\mathrm{D}_{\mathrm{x}}$, $\mathrm{x}$ is taller than $\mathrm{y}$ by exactly as much as $\mathrm{y}$ is shorter than $\mathrm{x}$ ). However, what is less for the positive adjective is more for its negative antonym (where $f_{\text {tall,t }}$ assigns smaller values, $f_{\text {short,t }}$ assigns bigger values). What kind of functions are linearly reversed in that sense, in comparison with, e.g., $\mathrm{f}_{\text {tall, } \mathrm{t}}$ ?

Let the function $f_{0-\text { tall }}$ be such that for any $x$ in $D_{x}$ it assigns the value $f_{\text {tall, }}$ assigns to $x$ multiplied by -1 (i.e., $\mathrm{f}_{0-\text { tall }}:=\lambda \mathrm{x} \in \mathrm{D}_{\mathrm{x}}$. $0-\mathrm{f}_{\text {tall, } \mathrm{t}}(\mathrm{x})$ ). Consider again the two equally tall entities $x_{1}$ and $x_{2}$ whose value in $f_{\text {tall, } t}$ is 5 .

$$
\begin{array}{ll}
\text { a. } & \mathrm{f}_{0-\text { tall }}\left(\mathrm{x}_{1}\right)=0-\mathrm{f}_{\text {tall, } \mathrm{t}}\left(\mathrm{x}_{1}\right)=-5 \\
\text { b. } & \mathrm{f}_{0-\text { tall }}\left(\mathrm{x}_{2}\right)=0-\mathrm{f}_{\text {tall, } \mathrm{t}}\left(\mathrm{x}_{2}\right)=-5 \\
\text { c. } & \mathrm{f}_{0-\text { tall }}\left(\mathrm{x}_{1} \oplus_{\text {height }} \mathrm{x}_{2}\right)=0-\mathrm{f}_{\text {tall, }}\left(\mathrm{x}_{1} \oplus_{\text {height }} \mathrm{x}_{2}\right)=-(5+5)=-10
\end{array}
$$

We see that, by its definition, $\mathrm{f}_{0-\text { tall }}$ is reversed in comparison with $\mathrm{f}_{\text {tall,t }}$ (while the latter assigns $\mathrm{x}_{1} \oplus_{\text {height }} \mathrm{x}_{2}$ a bigger degree than the one it assigns to $\mathrm{x}_{1}, 10>5$, the former assigns $\mathrm{x}_{1} \oplus_{\text {height }} \mathrm{x}_{2}$ a smaller degree, $-10<-5$ ). Furthermore, $\mathrm{f}_{0 \text {-tall }}$ is linearly reversed in comparison with $\mathrm{f}_{\text {tall, } \mathrm{t}}$ as the difference between these two degrees is preserved (the absolute difference between -10 and -5 is still 5). Finally, $\mathrm{f}_{0-\text { tall }}$ is additive. It maps all (and only) entities with no height to zero, it maps other equally tall entities to the same number (e.g., both $\mathrm{x}_{1}$ and $\mathrm{x}_{2}$ are mapped to -5 ), and it maps their concatenation to twice that number $\left(\mathrm{x}_{1} \oplus_{\text {height }} \mathrm{x}_{2}\right.$ is mapped to -10 which is precisely twice -5$)$.

However, there are many-in fact, infinitely many-other functions that are linearly reversed in comparison with $\mathrm{f}_{\text {tall,t }}$. For any real number Tran $\in \Re$, a function $\mathrm{f}_{\text {Tran-tall }}$ that assigns any $\mathrm{x}$ the degree $\left(\operatorname{Tran}-\mathrm{f}_{\text {tall, }}(\mathrm{x})\right.$ ) linearly reverses the degrees assigned by $\mathrm{f}_{\text {tall,t}}$. Moreover, only when the constant Tran is 0 (namely in $\mathrm{f}_{0-\text { tall }}$ ) is the function additive. Functions (whether reversed or not) that are transformed by a constant Tran $\neq 0$, like those in (10), do not adequately represent ratios between entities' heights.

$$
\begin{array}{lll}
\text { a. } & \mathrm{f}_{1-\text { tall }}:=\lambda \mathrm{x} \in \mathrm{D}_{\mathrm{x}} \cdot 1-\mathrm{f}_{\text {tall,t }}(\mathrm{x}) \\
\text { b. } & \mathrm{f}_{3.75-\text { tall }}:=\lambda \mathrm{x} \in \mathrm{D}_{\mathrm{x}} \cdot 3.75-\mathrm{f}_{\text {tall, } \mathrm{t}}(\mathrm{x}) \\
\text { c. } & \mathrm{f}_{-4-\text { tall }}:=\lambda \mathrm{x} \in \mathrm{D}_{\mathrm{x}} \cdot-4-\mathrm{f}_{\text {tall,t }}(\mathrm{x}) \\
\ldots & \\
\text { d. } & \forall \text { Tran } \in \Re, \mathrm{f}_{\text {Tran-tall }}\left(:=\lambda \mathrm{x} \in \mathrm{D}_{\mathrm{x}} . \text { Tran }-\mathrm{f}_{\text {tall, }}(\mathrm{x})\right) \text { linearly reverses } \mathrm{f}_{\text {tall, },} .
\end{array}
$$


The function in (10a), $f_{1-t a l l}$, maps any $x$ in $D_{x}$ to the constant $1-f_{\text {tall,t }}(x)$, i.e., the zero point is transformed (or displaced) by 1 . For example:

$$
\begin{array}{ll}
\text { a. } & \mathrm{f}_{1-\text { tall }}\left(\mathrm{x}_{1}\right)=1-\mathrm{f}_{\text {tall, } \mathrm{t}}\left(\mathrm{x}_{1}\right)=1-5=-4 \\
\text { b. } & \mathrm{f}_{1-\text { tall }}\left(\mathrm{x}_{2}\right)=1-\mathrm{f}_{\text {tall,t }}\left(\mathrm{x}_{2}\right)=1-5=-4 \\
\text { c. } & \mathrm{f}_{1-\text { tall }}\left(\mathrm{x}_{1} \oplus_{\text {height }} \mathrm{x}_{2}\right)=1-\mathrm{f}_{\text {tall, }}\left(\mathrm{x}_{1} \oplus_{\text {height }} \mathrm{x}_{2}\right)=1-10=-9
\end{array}
$$

This function is linearly reversed in comparison with $\mathrm{f}_{\text {tall,t }}$ (e.g., the absolute difference between -9 and -4 is still 5 ). However, the transformation value, 1 , functions as the 'local zero' (or the reference value), so entities with no height are mapped to ' 1 ', not ' 0 '. Thus, this function fails to be additive. The ratios between entities' degrees do not adequately represent the ratios between their heights; e.g., the ratio between the degrees of $\mathrm{x}_{1} \oplus \mathrm{x}_{2}$ and $\mathrm{x}_{1}$ is $9 / 4$ and the ratio between their heights is $8 / 4$.

Significantly, our intuitions do not tell us anything about negative adjectives, besides their being linearly reversed in comparison with their positive antonyms. In other words, we do not know which linearly reversed function they denote. In particular, we do not have intuitions that unequivocally tell us that the transformation value of short, $\operatorname{Tran}_{\text {short, }}$, is 0 , in every context $\mathrm{t}$ in $\mathrm{T}_{\mathrm{c}}$ of any actual context c. The transformation value is unspecified (index-dependent); i.e. for any actual context $\mathrm{c}$ the following holds:

$$
\text { Linear reversal: } \forall \mathrm{t} \in \mathrm{T}_{\mathrm{c}}, \exists \operatorname{Tran} \in \Re, \mathrm{f}_{\text {short }, \mathrm{t}}=\lambda \mathrm{x} \in \mathrm{D}_{\mathrm{x}} . \text { Tran }-\mathrm{f}_{\text {tall,t }}(\mathrm{x})
$$

(13) An undetermined transformation value:

$$
\neg \exists \operatorname{Tran} \in \Re, \forall \mathrm{t} \in \mathrm{T}_{\mathrm{c}}, \mathrm{f}_{\text {short }, \mathrm{t}}=\lambda \mathrm{x} \in \mathrm{D}_{\mathrm{x}} . \text { Tran }-\mathrm{f}_{\text {tall, } \mathrm{t}}(\mathrm{x})
$$

The basic motivation for this claim comes from intuitions corresponding to entities with, e.g., no height (surfaces and points). Our intuitions concerning their values (or lack thereof) directly reflect the unspecified transformation value of short.

Recall that in every completion $t$ of every context $c, f_{\text {tall, } t}$ is additive (it maps entities with no height to 0 ; cf. Sect. 3.1). Hence, short is not transformed in a context $\mathrm{c}\left(\operatorname{Tran}_{\text {short, }}=0\right.$ in every $\mathrm{t}$ of $\left.\mathrm{T}_{\mathrm{c}}\right)$ iff the degree of entities with no height $\mathrm{x}_{0}$ in short is known to be 0 in c (because in every $\mathrm{t} \in \mathrm{T}_{\mathrm{c}}$ it is $\operatorname{Tran}_{\text {short, }}-\mathrm{f}_{\text {tall, } \mathrm{t}}\left(\mathrm{x}_{0}\right)=0$ $0=0$ ). But is this so? Can we positively say that short maps entities with no height, such as the surface of the floor, to zero? (Or, in other words, that the surface of the floor is short to degree zero?) Not really. When I ask speakers to examine their intuitions regarding this issue, they are puzzled. They have absolutely no idea which entities are 'zero short', so to speak. This is the natural sign of an unspecified transformation value. The degree function of short transforms height quantities by a non-zero constant, $\operatorname{Tran}_{\text {short }}$. We know nothing about this constant (it may be any number). It varies across contexts in $\mathrm{T}_{\mathrm{c}}$, rendering the zero point undetermined. ${ }^{4}$

\footnotetext{
${ }^{4}$ Some semantic theories (von Stechow 1984b; Kennedy 1999) endorse the view that entities with (almost) no height are mapped to (a degree that approximates) infinity (formally, the largest interval $(0, \propto)$, not the zero interval $(0,0))$. Hence, in these theories as well, short transforms height values by a non-zero constant.
} 
Some readers may object to the assumption that $\mathrm{f}_{\text {tall }}$ is defined for entities with no height, given that sentences such as This idea is zero centimeters tall or This surface is zero inches tall are unacceptable (cf. Kennedy 2007). But note that the infelicity of the former can be explained by the inapplicability of the measurement method (a ruler) to ideas, and the infelicity of the latter can be explained by a triviality filter (it is never informative enough; cf. Fox and Hackl 2006). While the issue whether, e.g., ideas are part of the domain of tall or not is outside the scope of this paper, for my argument to go through it is sufficient that rulers do have a value ' 0 ', that this measurement method is applicable for surfaces, and that when appropriately applied to surfaces it yields just this value, ' 0 ' (regardless of the reasons why the above statements may be inappropriate). The situation is rather different for short, where no such convention or intuition about the zero exist. In fact, statements like This surface is zero inches short are not only inappropriate, but also senseless. Intuitively, the location of the zero point in adjectives like short is uncertain. To represent this fact, the degree functions of negative adjectives should be transformed by an unspecified constant. ${ }^{5}$

Thus, the least tall entities are the shortest, but their degrees in tall and short are not the same, because reversed functions are also transformed. But why are they transformed? Positive numbers are easier to work with. We usually use negative adjectives like short to discuss heights of people, furniture, or buildings, but not, say, planets or universes. Hence, a viable possibility is that the reversed functions associated with short are transformed in order to turn positive the values of at least those entities that are usually under discussion - those that we might rank as short or not short (see more on this role of transformation values in Sects. 5.3-5.4).

Let $\mathrm{M}_{\mathrm{C}}$ be a model for a set of contexts $\mathrm{C}$, with a set of completions $\mathrm{T} \subseteq \mathrm{C}$ (cf. (5)-(7) above). The function of transformation values can be made explicit by adding to the definition of a model a function ' $f$ ' (ADJ $\left.\times \mathrm{T} \rightarrow \Re^{\mathrm{Dx}}\right)$, from adjectives $\mathrm{A} \in \mathrm{ADJ}$ and completions $\mathrm{t} \in \mathrm{T}$ into base functions, $f(\mathrm{~A}, \mathrm{t}) \in \Re^{\mathrm{Dx}}$, and a function 'Tran' (ADJ $\times \mathrm{T} \rightarrow \Re$ ), from adjectives $\mathrm{A} \in \mathrm{ADJ}$ and completions $\mathrm{t} \in$ $\mathrm{T}$ into transformation values, $\operatorname{Tran}(\mathrm{A}, \mathrm{t}) \in \Re$ (called ' $\operatorname{Tran}_{\mathrm{A}, \mathrm{t}}{ }^{\prime}$ ), such that for any $\mathrm{t} \in \mathrm{T}$ :

(14) Antonymy and polarity:

a. If $\mathrm{A}$ and $\mathrm{B}$ are antonyms, their base functions are identical: $f(\mathrm{~B}, \mathrm{t})=f(\mathrm{~A}, \mathrm{t})$.

b. If $\mathrm{A}$ is positive, $\quad \mathbf{f}_{\mathbf{A}, \mathbf{t}}=\lambda \mathbf{x} \in \mathbf{D}_{\mathbf{x}} \cdot f(\mathbf{A}, \mathbf{t})(\mathbf{x})-\operatorname{Tran}_{\mathbf{A}, \mathbf{t}}$

c. If B is negative, $\quad \mathbf{f}_{\mathbf{B}, \mathbf{t}}=\lambda \mathbf{x} \in \mathbf{D}_{\mathbf{x}}$. $\operatorname{Tran}_{\mathbf{B}, \mathbf{t}}-f(\mathbf{B}, \mathbf{t})(\mathbf{x})$

d. If $\mathrm{A}, \mathrm{B}$ form a paradigmatic antonym pair and $\mathrm{A}$ is positive:

$f(\mathbf{A}, \mathbf{t})$ is additive and $\operatorname{Tran}_{\mathbf{A}, \mathbf{t}}=\mathbf{0}$

\footnotetext{
5 Domains of measure functions may be restricted (Kennedy 2007). However, we do have clearer intuitions about zero points in adjectives like tall than in adjectives like short or warm, a fact that cannot be captured if all exclude the zero point from their scale in the first place. Perhaps, then, while the domain of $\mathrm{f}_{\text {tall }}$ is unrestricted (it maps all abstract entities to zero), the interpretation of tall is not $\mathrm{f}_{\text {tall, } \mathrm{t}}$ itself, but rather, $\lambda \mathrm{x}$, s.t. $\mathrm{f}_{\text {tall }, \mathrm{t}}(\mathrm{x}) \neq 0 . \mathrm{f}_{\text {tall }, \mathrm{t}}(\mathrm{x})$.
} 
Thus, in every t, $f$ associates tall and short with one and the same base function $f($ tall, $\mathrm{t})=f($ short, $\mathrm{t})(\mathrm{cf} .(14 \mathrm{a}))$, namely, one of the functions that adequately represent height. However, unlike $\mathrm{f}_{\text {tall, },}, \mathrm{f}_{\text {short, } t}$ is reversed in comparison to their base function (cf. $(14 \mathrm{~b}, \mathrm{c}))$. Furthermore, the transformation value of paradigmatic positive adjectives like tall is zero (cf. (14d)), meaning that in degree constructions tall ultimately denotes its contextually given additive base function, $\llbracket$ tall $\rrbracket_{\mathbf{t}}=\mathbf{f}_{\text {tall, } \mathbf{t}}=f($ tall, $\mathbf{t})$. Conversely, the transformation value of negative adjectives is unspecified (completion-variant), meaning that in degree constructions adjectives like short ultimately denote a degree function that is virtually always transformed in comparison with the base function, $\llbracket$ short $\rrbracket_{\mathbf{t}}=\mathbf{f}_{\text {short }, \mathbf{t}}=\lambda \mathbf{x} \in \mathbf{D}_{\mathbf{x}}$. Tran $_{\text {short,t }}-f\left(\right.$ tall,t)(x). ${ }^{6}$

Note: To avoid confusion, whenever I say, e.g., "the degree function of short", I refer to the final, reversed, and transformed function, $\mathrm{f}_{\text {short, }}$, not to the additive base function, $f($ short, $\mathrm{t})$. Furthermore, since the latter equals $\mathrm{f}_{\text {tall, }}, \mathrm{I}$ never refer to it by writing ' $f\left(\right.$ short,t)', only ' $\mathrm{f}_{\text {tall,t }}$ ' (same with $f($ tall,t $)$ ).

Now that we have motivated transformation values (by our uncertainty concerning which entities are mapped to zero), Sect. 4 explores their predictive fruitfulness.

\section{Direct results}

Let us examine the workings of a simplified context c, represented by three possible completions $\left(\mathrm{T}_{\mathrm{c}}=\left\{\mathrm{t}_{1}, \mathrm{t}_{2}, \mathrm{t}_{3}\right\}\right)$. $^{7}$ Let the domain of discourse consist of three entities $\left(D_{x}=\left\{x_{1}, x_{2}, x_{3}\right\}\right)$, where $x_{1}$ is an inch unit-object, and $x_{2}$ and $x_{3}$ constitute the ostrich and the chicken from Sect. 2, respectively. Tables 1 and 2 present the mapping functions of tall and short in c, respectively.

On the one hand, the functions associated with the positive adjective tall in c are all additive. Their transformation value equals zero (none has a 'transformed local zero', so to speak). Hence, they all adequately represent the ratios and differences between entities' heights. For instance, the fact that in $\mathrm{c}$ the height of the ostrich, $\mathrm{x}_{2}$, is twice the height of the chicken, $\mathrm{x}_{3}$, and sixty times the height of the inch, $\mathrm{x}_{1}$, is represented by the fact that in every $t$ of $\mathrm{T}_{\mathrm{c}}, \mathrm{f}_{\mathrm{tall}, \mathrm{t}}\left(\mathrm{x}_{2}\right)$ (the value tall assigns to the ostrich) is twice $\mathrm{f}_{\text {tall, } \mathrm{t}}\left(\mathrm{x}_{3}\right)$ (the value tall assigns to the chicken), and sixty times $\mathrm{f}_{\text {tall, } \mathrm{t}}\left(\mathrm{x}_{1}\right)$ (the value tall assigns to the inch); e.g., in $\mathrm{t}_{1}, \mathrm{f}_{\mathrm{tall}, \mathrm{t} 1}\left(\mathrm{x}_{2}\right)=60=$ $2 \mathrm{f}_{\text {tall }, \mathrm{t} 1}\left(\mathrm{x}_{3}\right)=2 \times 30=60 \mathrm{f}_{\text {tall }, \mathrm{t} 1}\left(\mathrm{x}_{1}\right)=60 \times 1$.

\footnotetext{
${ }^{6}$ Unless contexts c bias towards a non-transformed interpretation (cf. Sect. 5.4), the chances that $\operatorname{Tran}_{\text {short, }}=0$ in a completion $\mathrm{t}$ are $1 / / \Re$, i.e., very close to zero.

${ }^{7}$ An actual context is consistent with infinitely many completions, but three suffice to demonstrate our main points.
} 
Table 1 Functions associated with tall in c based on additive measures (possible rulers)

\begin{tabular}{lllll}
\hline $\mathrm{f}_{\text {tall, } \mathrm{t}}$ & $\begin{array}{l}\text { Transformation } \\
\text { value of tall in } \mathrm{t} \\
\text { Tran }_{\text {tall, } \mathrm{t}}\end{array}$ & $\begin{array}{l}\text { Inch } \\
\text { unit-object } \\
\mathrm{x}_{1}\end{array}$ & $\begin{array}{l}\text { Ostrich } \\
\text { from Sect. 2 } \\
\mathrm{x}_{2}\end{array}$ & $\begin{array}{l}\text { Chicken } \\
\text { from Sect. 2 } \\
\mathrm{x}_{3}\end{array}$ \\
\hline $\mathrm{t}_{1}$ & $\mathbf{0}$ & 1 & 60 & 30 \\
$\mathrm{t}_{2}$ & $\mathbf{0}$ & 2 & 120 & 60 \\
$\mathrm{t}_{3}$ & $\mathbf{0}$ & 3 & 180 & 90 \\
\hline
\end{tabular}

Table 2 Functions associated with short in $\mathrm{c}$ based on function reversal: $\forall \mathrm{t} \in \mathrm{T}_{\mathrm{c}}, \forall \mathrm{x} \in \mathrm{D}_{\mathrm{x}}$, $\mathrm{f}_{\text {short }, \mathrm{t}}(\mathrm{x})=\operatorname{Tran}_{\text {short }, \mathrm{t}}-\mathrm{f}_{\text {tall, }, \mathrm{t}}(\mathrm{x})$

\begin{tabular}{lllll}
\hline $\mathrm{f}_{\text {short } \mathrm{t}}$ & $\begin{array}{l}\text { Transformation value } \\
\text { of short in } \mathrm{t}, \mathrm{Tran}_{\text {short }, \mathrm{t}}\end{array}$ & $\begin{array}{l}\text { Inch unit-object } \\
\mathrm{x}_{1}\end{array}$ & $\begin{array}{l}\text { Ostrich } \\
\mathrm{x}_{2}\end{array}$ & $\begin{array}{l}\text { Chicken } \\
\mathrm{x}_{3}\end{array}$ \\
\hline $\mathrm{t} 1$ & $\mathbf{1 0}$ & $10-1=\mathbf{9}$ & $10-60=-\mathbf{5 0}$ & $10-30=-\mathbf{2 0}$ \\
$\mathrm{t} 2$ & $\mathbf{0}$ & $0-2=-\mathbf{2}$ & $0-120=-\mathbf{1 2 0}$ & $0-60=-\mathbf{6 0}$ \\
$\mathrm{t} 3$ & $\mathbf{- 1 0}$ & $-10-3=-\mathbf{1 3}$ & $-10-180=-\mathbf{1 9 0}$ & $-10-90=-\mathbf{1 0 0}$ \\
\hline
\end{tabular}

On the other hand, the functions associated with the negative adjective short in c are not straightforwardly based on possible additive measuring conventions. Rather, they are based on linear function reversal. Most of the linearly reversed functions are also transformed. In completions $\mathrm{t}_{1}$ and $\mathrm{t}_{3}$, then, the reversed values short assigns are transformed by a non-zero constant. Consequently, they fail to represent height ratios. For example, the transformation value of short in $\mathrm{t}_{1}, \operatorname{Tran}_{\text {short,t1 }}$, is 10 ; consequently, in $\mathrm{t}_{1}$ short assigns the ostrich $\mathrm{x}_{2}$ the degree $10-\mathrm{f}_{\text {tall,t1 }}\left(\mathrm{x}_{2}\right)=10-$ $60=-50$, which is not twice the degree it assigns to the chicken, $10-$ $\mathrm{f}_{\text {tall,t } 1}\left(\mathrm{x}_{3}\right)=10-30=-20$.

I will now demonstrate how the following generalizations are accounted for:

(i) the infelicity of ratio-modifiers with default interpretations of negative adjectives (Sect. 4.1);

(ii) the incompatibility of numerical degree modifiers with negative adjectives (Sect. 4.2);

(iii) the compatibility of numerical degree modifiers with derived comparatives of negative adjectives (Sect. 4.3); and

(iv) the infelicity of cross-polar comparisons (Sect. 4.4).

\subsection{Ratio modifiers}

This subsection shows that lack of additivity due to unspecified transformation values yields ratio modifiers infelicitous.

I adopt the widely employed view that comparison statements involve the application of a difference operation (von Stechow 1984b; Schwarzschild and Wilkinson 2002; Kennedy and McNally 2005; Schwarzschild 2005; Kennedy and 
Levin 2008, p. 17). I take comparison statements like Dan is taller than Sam (by 2 inches) to hold true in a completion t iff the difference between Dan and Sam's degrees in $\mathrm{t}$ is a positive real number (twice the degree of an inch unit object in $\mathrm{t}$; $\mathrm{cf}$. (15)). Similarly, I take ratio statements to involve the application of a ratio operation (von Stechow 1984b), namely, Dan is twice as tall as Sam holds true in t iff Dan's degree equals twice Sam's in t.

$\llbracket$ Dan is 2 inches taller than $\operatorname{Sam} \rrbracket_{\mathrm{t}}=1$ iff $\mathrm{f}_{\text {tall, } \mathrm{t}}\left(\llbracket\right.$ Dan $\left.\rrbracket_{\mathrm{t}}\right)-\mathrm{f}_{\text {tall, }}\left(\llbracket\right.$ Sam $\left.\rrbracket_{\mathrm{t}}\right)$ $=2 r_{\text {inch,t }}$ (where $r_{\text {inch,t }}$ is the degree of height of an inch unit-object in $t$ )

$$
\llbracket \text { Dan is twice as tall as Sam } \rrbracket_{\mathrm{t}}=1 \text { iff } \mathrm{f}_{\text {tall, } \mathrm{t}}\left(\llbracket \text { Dan } \rrbracket_{\mathrm{t}}\right)=2 \times \mathrm{f}_{\text {tall, } \mathrm{t}}\left(\llbracket \operatorname{Sam} \rrbracket_{\mathrm{t}}\right)
$$

The basic interpretation of phrasal $e r$ as a difference operation is $\lambda \mathrm{r}_{2} \in \Re . \lambda$ $\mathrm{M}_{\langle\mathrm{r}, \mathrm{t}\rangle} \cdot \lambda \mathrm{r}_{1} \in \Re . \mathrm{M}\left(\mathrm{r}_{1}-\mathrm{r}_{2}\right)$ (where the variable $\mathrm{M}$ has to be saturated by a degree predicate like two inches; cf. Schwarzschild and Wilkinson 2002; Landman 2005), and the interpretation of as is $\lambda \mathrm{r}_{2} \in \Re . \lambda \mathrm{r}_{1} \in \Re$. $\llbracket e r \rrbracket\left(\mathrm{r}_{2}, \lambda \mathrm{r} . \mathrm{r} \geq 0, \mathrm{r}_{1}\right)$, which reduces to: $\lambda r_{2} \cdot \lambda r_{1} \cdot r_{1}-r_{2} \geq 0$. Given the latter, $I$ assume that normally, the use of the comparative rather than the equative excludes the possibility that $\mathrm{M}$ is $\lambda$ r.r $\geq 0$; i.e., in the absence of an overt numerical degree modification, $\mathrm{M}$ is saturated by the predicate $\lambda \mathrm{r} \in \Re . \mathrm{r}>0$ (implying that $\mathrm{r}_{1}-\mathrm{r}_{2}>0$ ), as illustrated below. Finally, when er combines with an adjective as in taller, interpretation type shifts to an individual level: $\lambda \mathrm{f} \in \Re^{\mathrm{Dx}} \cdot \lambda \mathrm{x}_{2} \in \mathrm{D}_{\mathrm{x}} \cdot \lambda \mathrm{M} \cdot \lambda \mathrm{x}_{1} \in \mathrm{D}$. «er $\left(\mathrm{f}\left(\mathrm{x}_{2}\right)\right)(\mathrm{M})\left(\mathrm{f}\left(\mathrm{x}_{1}\right)\right)$, which reduces to $\lambda \mathrm{f} \in \Re^{\mathrm{Dx}} . \lambda \mathrm{x}_{2} \in \mathrm{D}_{\mathrm{x}} \cdot \lambda \mathrm{M} \cdot \lambda \mathrm{x}_{1} \in \mathrm{D}_{\mathrm{x}} \cdot \mathrm{M}\left(\mathrm{f}\left(\mathrm{x}_{1}\right)-\mathrm{f}\left(\mathrm{x}_{2}\right)\right){ }^{8}$

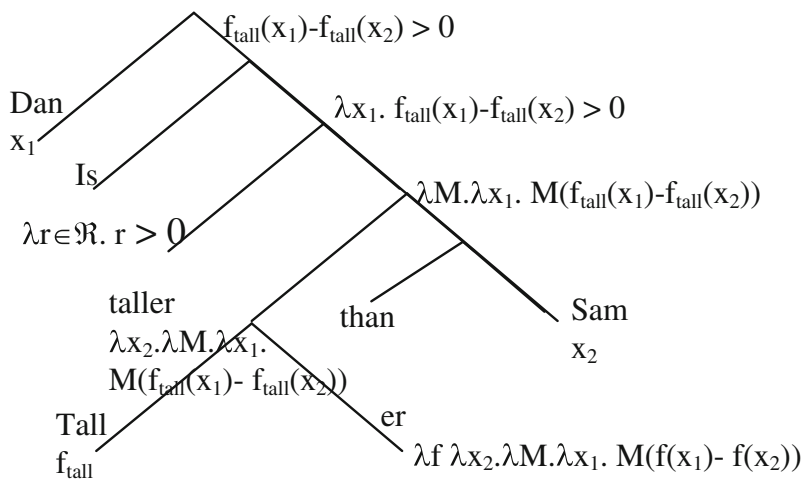

Ratio morphemes like twice are modifiers of difference morphemes (usually in English, the equative as). ${ }^{9}$ The interpretation of twice in each $\mathrm{t}$ is $\lambda \mathrm{C}_{\langle\mathrm{r},\langle\mathrm{r}, \mathrm{t}\rangle\rangle} . \lambda \mathrm{f} \in$ $\Re^{\mathrm{Dx}} \cdot \lambda \mathrm{x}_{2} \in \mathrm{D}_{\mathrm{x}} \cdot \lambda \mathrm{x}_{1} \in \mathrm{D}_{\mathrm{x}} \cdot \mathrm{C}\left(2 \mathrm{f}\left(\mathrm{x}_{2}\right)\right)\left(\mathrm{f}\left(\mathrm{x}_{1}\right)\right)$, where the variable $\mathrm{C}$ has to be saturated by basic interpretations of difference morphemes (e.g., as). The interpretation of twice as tall, $\llbracket$ twice $\rrbracket_{\mathrm{t}}\left(\llbracket\right.$ as $\left.\rrbracket_{\mathrm{t}}\right)\left(\llbracket\right.$ tall $\left.\rrbracket_{\mathrm{t}}\right)$, then, reduces to $\lambda \mathrm{x}_{2} \in \mathrm{D}_{\mathrm{x}} \cdot \lambda \mathrm{x}_{1} \in \mathrm{D}_{\mathrm{x}} \cdot \mathrm{f}_{\mathrm{tall}, \mathrm{t}}\left(\mathrm{x}_{1}\right)$ $-2 \times \mathrm{f}_{\text {tall, } \mathrm{t}}\left(\mathrm{x}_{2}\right) \geq 0$, as illustrated in (18).

\footnotetext{
${ }^{8}$ For an analysis of clausal comparisons see Sect. 4.4.

9 In English, unlike Russian or Hebrew, the equative is often preferred to the comparative, but both forms exist.
} 


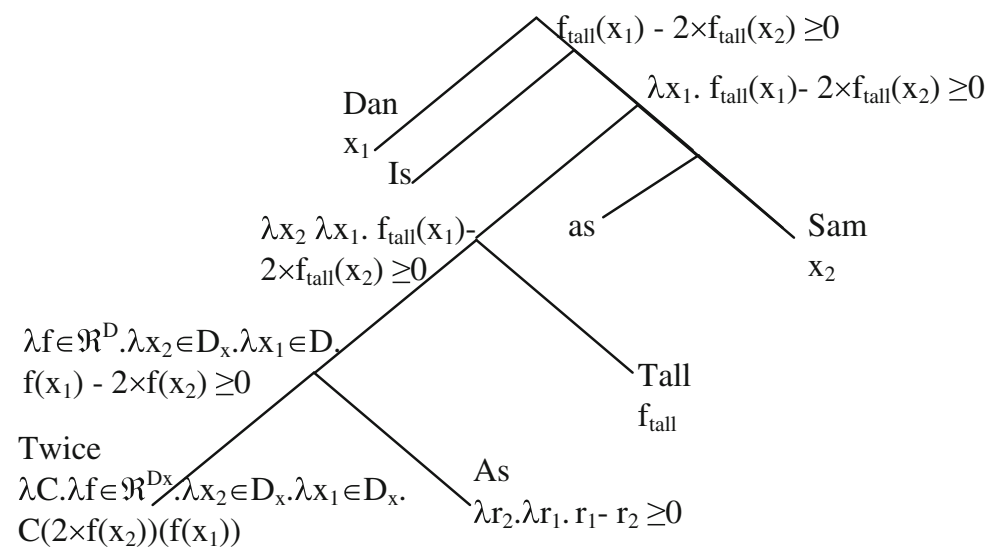

Why do negative adjectives like short tend not to combine with ratio modifiers like twice? In order to see this, let us first focus on tall. Recall that the ostrich has double height compared with the chicken in c. The degree function of tall adequately represents this fact given that in every context $\mathrm{t}$ in $\mathrm{T}_{\mathrm{c}}$, tall maps the chicken to some number $\mathrm{r}$, and the ostrich to twice that number, $2 \mathrm{r}$ (cf. (19)). As a result, the statement The ostrich is twice as tall as the chicken is true in c (cf. (20)):

$$
\begin{aligned}
& \text { a. } \mathrm{f}_{\text {tall, } \mathrm{t1}}\left(\mathrm{x}_{2}\right)=\mathbf{6 0} \quad \mathrm{f}_{\text {tall,t1 }}\left(\mathrm{x}_{3}\right)=\mathbf{3 0} \Rightarrow \mathrm{f}_{\text {tall,t1 }}\left(\mathrm{x}_{2}\right)=2 \times \mathrm{f}_{\text {tall, t1 }}\left(\mathrm{x}_{3}\right) \\
& \text { b. } \mathrm{f}_{\text {tall, } \mathrm{t} 2}\left(\mathrm{x}_{2}\right)=\mathbf{1 2 0} \quad \mathrm{f}_{\text {tall, } \mathrm{t} 2}\left(\mathrm{x}_{3}\right)=\mathbf{6 0} \Rightarrow \mathrm{f}_{\text {tall, } \mathrm{t} 2}\left(\mathrm{x}_{2}\right)=2 \times \mathrm{f}_{\text {tall,t2 }}\left(\mathrm{x}_{3}\right) \\
& \text { c. } \mathrm{f}_{\text {tall, }, \mathrm{t} 3}\left(\mathrm{x}_{2}\right)=\mathbf{1 8 0} \quad \mathrm{f}_{\mathrm{tall}, \mathrm{t} 3}\left(\mathrm{x}_{3}\right)=\mathbf{9 0} \Rightarrow \mathrm{f}_{\mathrm{tall}, \mathrm{t} 3}\left(\mathrm{x}_{2}\right)=2 \times \mathrm{f}_{\text {tall, } \mathrm{t3}}\left(\mathrm{x}_{3}\right)
\end{aligned}
$$

(20) $\llbracket$ The ostrich is twice as tall as the chicken $\rrbracket_{\mathrm{c}}=1 \quad$ iff $\forall \mathrm{t} \in \mathrm{T}_{\mathrm{c}}$, The ostrich is twice as tall as the chicken $\rrbracket_{\mathrm{t}}=1$ iff $\forall \mathrm{t} \in \mathrm{T}_{\mathrm{c}}, \mathrm{f}_{\mathrm{tall}, \mathrm{t}}\left(\llbracket\right.$ The ostrich $\left.\rrbracket_{\mathrm{t}}\right)=2 \times \mathrm{f}_{\mathrm{tall}, \mathrm{t}}\left(\llbracket\right.$ The chicken $\left.\rrbracket_{\mathrm{t}}\right) \quad$ iff $\forall \mathrm{t} \in \mathrm{T}_{\mathrm{c}}, \mathrm{f}_{\text {tall, } \mathrm{t}}\left(\mathrm{x}_{2}\right)=2 \times \mathrm{f}_{\mathrm{tall}, \mathrm{t}}\left(\mathrm{x}_{3}\right)$

The situation differs with regard to the negative adjective short, whose degree function is reversed and transformed by a value that is unspecified in c. In every $t$ in $\mathrm{T}_{\mathrm{c}}$ in which tall maps the chicken to $\mathrm{r}$ and the ostrich to $2 \mathrm{r}$, short maps the chicken to $\operatorname{Tran}_{\text {short,t }}-\mathrm{r}$ and the ostrich to $\operatorname{Tran}_{\text {short,t }}-2 \mathrm{r}$. But none of these two degrees, $\operatorname{Tran}_{\text {short, } t}-\mathrm{r}$ and $\operatorname{Tran}_{\text {short }, \mathrm{t}}-2 \mathrm{r}$, is twice the other, unless $\operatorname{Tran}_{\text {short,t }}=0$ (cf. (21)). Since it is not the case that the ostrich's degree in short equals twice the chicken's in every $\mathrm{t}$ in $\mathrm{T}_{\mathrm{c}}$ (e.g., in $\mathrm{t}_{1}$ and $\mathrm{t}_{3}$ it doesn't), the statement The ostrich is twice as short as the chicken is not true in c (cf. (22)). And since it is not the case that the ostrich's degree in short does not equal twice the chicken's in every $\mathrm{t}$ in $\mathrm{T}_{\mathrm{c}}$ (e.g., in $\mathrm{t}_{2}$ it does), The ostrich is twice as short as the chicken is not false in c (cf. (23)).

$$
\begin{aligned}
& \text { a. } \quad \mathrm{f}_{\text {short }, \mathrm{t} 1}\left(\mathrm{x}_{2}\right)=\operatorname{Tran}_{\text {short }, \mathrm{t} 1}-\mathrm{f}_{\text {tall, } \mathrm{t} 1}\left(\mathrm{x}_{2}\right)=10-60=\mathbf{- 5 0} \\
& \mathrm{f}_{\text {short }, \mathrm{t} 1}\left(\mathrm{x}_{3}\right)=\operatorname{Tran}_{\text {short,t1 }}-\mathrm{f}_{\text {tall, } \mathrm{t} 1}\left(\mathrm{x}_{3}\right)=10-30=-\mathbf{2 0} \Rightarrow \\
& \mathrm{f}_{\text {tall,t1 }}\left(\mathrm{x}_{2}\right) \neq 2 \times \mathrm{f}_{\text {tall,t1 }}\left(\mathrm{x}_{3}\right)
\end{aligned}
$$




$$
\begin{aligned}
& \text { b. } \mathrm{f}_{\text {short }, \mathrm{t} 2}\left(\mathrm{x}_{2}\right)=\operatorname{Tran}_{\text {short, } \mathrm{t} 2}-\mathrm{f}_{\text {tall, } \mathrm{t} 2}\left(\mathrm{x}_{2}\right)=0-120=\mathbf{- 1 2 0} \\
& \mathrm{f}_{\text {short }, \mathrm{t} 2}\left(\mathrm{x}_{3}\right)=\operatorname{Tran}_{\text {short }, \mathrm{t} 2}-\mathrm{f}_{\text {tall, } \mathrm{t} 2}\left(\mathrm{x}_{3}\right)=0-60=-\mathbf{6 0} \Rightarrow \\
& \mathrm{f}_{\text {tall, t2 }}\left(\mathrm{x}_{2}\right)=2 \times \mathrm{f}_{\text {tall,t2 }}\left(\mathrm{x}_{3}\right) \\
& \text { c. } \mathrm{f}_{\text {short }, \mathrm{t} 3}\left(\mathrm{x}_{2}\right)=\operatorname{Tran}_{\text {short }, \mathrm{t} 3}-\mathrm{f}_{\text {tall, } \mathrm{t} 3}\left(\mathrm{x}_{2}\right)=-10-180=\mathbf{- 1 9 0} \\
& \mathrm{f}_{\text {short }, \mathrm{t} 3}\left(\mathrm{x}_{3}\right)=\operatorname{Tran}_{\text {short }, \mathrm{t} 3}-\mathrm{f}_{\text {tall, } \mathrm{t} 3}\left(\mathrm{x}_{3}\right)=-10-90=-\mathbf{1 0 0} \Rightarrow \\
& \mathrm{f}_{\text {tall, } \mathrm{t} 3}\left(\mathrm{x}_{2}\right) \neq 2 \times \mathrm{f}_{\text {tall, }, \mathrm{t} 3}\left(\mathrm{x}_{3}\right)
\end{aligned}
$$

(22) $\llbracket$ The ostrich is twice as short as the chicken $\rrbracket_{\mathrm{c}}=1 \quad$ iff

$\forall \mathrm{t} \in \mathrm{T}_{\mathrm{c}}$, The ostrich is twice as short as the chicken $\rrbracket_{\mathrm{t}}=1$ iff

$\forall \mathrm{t} \in \mathrm{T}_{\mathrm{c}}, \mathrm{f}_{\text {short } \mathrm{t}}\left(\llbracket\right.$ The ostrich $\left.\rrbracket_{\mathrm{t}}\right)=2 \times \mathrm{f}_{\text {short, } \mathrm{t}}\left(\llbracket\right.$ The chicken $\left.\rrbracket_{\mathrm{t}}\right) \quad$ iff

$\forall \mathrm{t} \in \mathrm{T}_{\mathrm{c}}, \operatorname{Tran}_{\text {short, } \mathrm{t}}-\mathrm{f}_{\mathrm{tall}, \mathrm{t}}\left(\llbracket\right.$ The ostrich $\left.\rrbracket_{\mathrm{t}}\right)=$

$2 \times\left(\operatorname{Tran}_{\text {short }, \mathrm{t}}-\mathrm{f}_{\text {tall, } \mathrm{t}}\left(\llbracket\right.\right.$ The chicken $\left.\left.\rrbracket_{\mathrm{t}}\right)\right)$ iff

$\forall \mathrm{t} \in \mathrm{T}_{\mathrm{c}}, \operatorname{Tran}_{\text {short,t }}-\mathrm{f}_{\text {tall, }}\left(\mathrm{x}_{2}\right)=2 \times \operatorname{Tran}_{\text {short } \mathrm{t}}-2 \times \mathrm{f}_{\text {tall, } \mathrm{t}}\left(\mathrm{x}_{3}\right)$ iff

$\forall \mathrm{t} \in \mathrm{T}_{\mathrm{c}}, 2 \times \mathrm{f}_{\text {tall, } \mathrm{t}}\left(\mathrm{x}_{3}\right)-\mathrm{f}_{\text {tall, } \mathrm{t}}\left(\mathrm{x}_{2}\right)=\operatorname{Tran}_{\text {short }, \mathrm{t}}$

(23) 【The ostrich is twice as short as the chicken $\rrbracket_{\mathrm{c}}=0 \quad$ iff

$\forall \mathrm{t} \in \mathrm{T}_{\mathrm{c}}$, $\llbracket$ The ostrich is twice as short as the chicken $\rrbracket_{\mathrm{t}}=0$ iff

$\forall \mathrm{t} \in \mathrm{T}_{\mathrm{c}}, \mathrm{f}_{\text {short, } \mathrm{t}}\left(\llbracket\right.$ The ostrich $\left.\rrbracket_{\mathrm{t}}\right) \neq 2 \times \mathrm{f}_{\text {short }, \mathrm{t}}\left(\llbracket\right.$ The chicken $\left.\rrbracket_{\mathrm{t}}\right) \quad$ iff

$\forall \mathrm{t} \in \mathrm{T}_{\mathrm{c}}, 2 \times \mathrm{f}_{\text {tall,t }}\left(\mathrm{x}_{3}\right)-\mathrm{f}_{\text {tall,t }}\left(\mathrm{x}_{2}\right) \neq \operatorname{Tran}_{\text {short }, \mathrm{t}}$

We see that ratio statements with negative adjectives can be neither verified nor falsified in c. In fact, in both their truth conditions and their falsity conditions ((22)(23)), a meta-language variable occurs, $\operatorname{Tran}_{\text {short }}$. Its value is unspecified in c (it varies across $T_{c}$ ), rendering the truth value of such statements inherently undetermined. As this is the case in every actual context $\mathrm{c}$ where negative adjectives like short receive their default (reversed and transformed) interpretation, ratio statements are (by default) uninterpretable with negative adjectives.

\subsection{Numerical degree modifiers}

The present proposal directly predicts the indeterminacy of the degrees negative adjectives assign and, consequently, their incompatibility with numerical degree modifiers.

Let unit nouns like meters belong to a nominal category UNIT, and their semantics be based on measurement theory (Krantz et al. 1971; Klein 1991), as follows. ${ }^{10}$

First, unit nouns are lexically related to a set of dimensions A, e.g., gradable adjectives like tall, wide, long, etc. (cf. Murphy 2006). Per a dimension A, unit nouns are directly linked to a set of entities, which, by virtue of a convention, are regarded as unit objects relative to $A$. For example, the set of unit objects of the noun meter relative to the dimension tall, $\mathrm{D}_{\mathrm{m} \text {, tall }}$, consists of the entities

\footnotetext{
$\overline{{ }^{10} \text { For a lengthy justification of this analysis see Sassoon }(2007,2010) .}$
} 
whose height we call 'one meter' (e.g., the meter bar in Paris). This set is convention based (and therefore completion invariant) in actual contexts. ${ }^{11}$

Second, in any completion $\mathrm{t}$, let $\mathrm{r}_{\mathrm{m}, \mathrm{t}} \in \Re$ stand for the non-zero degree the dimensions of meter assign to their unit objects in t. ${ }^{12}$ Generally, for any unit $\in$ UNIT:

Set of unit objects

Let $\mathrm{D}_{\mathrm{u}, \mathrm{A}} \subseteq \mathrm{D}_{\mathrm{x}}$ be the set of unit objects of unit relative to dimension $\mathrm{A}$.

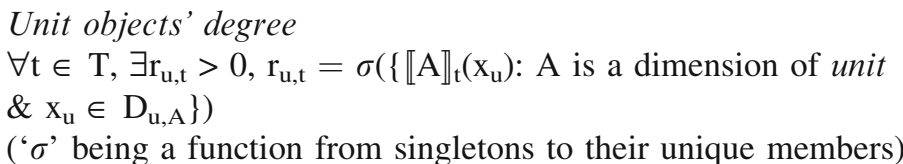

Finally, like numerals and difference morphemes, unit nouns are ambiguous between a number-level interpretation, meter $_{\text {num }}$, and an individual-level interpretation, meters $s_{\text {ind }}$ (Landman 2005). ${ }^{13}$ The basic, number-level interpretation of a unit

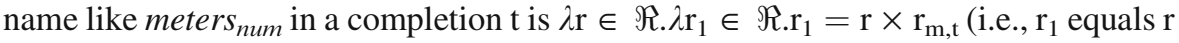
times the value of a meter unit-object, $\left.r_{m, t}\right)$. Accordingly, the individual-level interpretation of meters in any context $\mathrm{t}$ is $\lambda \mathrm{r} \in \Re . \lambda \mathrm{f} \in \Re^{\mathrm{Dx}} . \lambda \mathrm{x} \in \mathrm{D}_{\mathrm{x}} \cdot \llbracket$ meter $_{\text {num }} \rrbracket_{\mathrm{t}}(\mathrm{r}, \mathrm{f}(\mathrm{x}))$, which reduces to $\lambda \mathrm{r} \in \Re . \lambda \mathrm{f} \in \Re^{\mathrm{Dx}} . \lambda \mathrm{x} \in \mathrm{D}_{\mathrm{x}} . \mathrm{f}(\mathrm{x})=\mathrm{r} \times \mathrm{r}_{\mathrm{m}, \mathrm{t}}$. The variable ' $\mathrm{f}$ ' can only be saturated by a dimension of meter in $\mathrm{t}\left(\mathrm{e} . \mathrm{g}\right.$., $\left.\mathrm{f}_{\text {tall }, t}, \mathrm{f}_{\text {wide }, t}, \mathrm{f}_{\text {long, },}\right)$; $\mathrm{f}$ assigns $\mathrm{x}$ a value that equals $r$ times the value of a meter unit-object, $r_{m, t}$. Generally:

\section{Numerical degree predicates}

$\forall \mathrm{t} \in \mathrm{T}$, for any unit $\in \mathrm{UNIT}$, adjectival dimension $\mathrm{P}$ of unit, and numeral $\mathrm{r}$ : $\llbracket \mathrm{r}_{\text {unit }_{\text {ind }}} \mathrm{P} \rrbracket_{\mathrm{t}}=\llbracket$ unit $_{\text {ind }} \rrbracket_{\mathrm{t}}\left(\llbracket \mathrm{r} \rrbracket_{\mathrm{t}}\right)\left(\llbracket \mathrm{P} \rrbracket_{\mathrm{t}}\right)$

$$
\begin{aligned}
& =\lambda \mathrm{x} \in \mathrm{D}_{\mathrm{x}} \cdot \llbracket \mathrm{P} \rrbracket_{\mathrm{t}}(\mathrm{x})=\llbracket \mathrm{r} \rrbracket_{\mathrm{t}} \times \mathrm{r}_{\mathrm{u}, \mathrm{t}} \\
& =\lambda \mathrm{x} \in \mathrm{D}_{\mathrm{x}} \cdot \mathrm{f}_{\mathrm{P}, \mathrm{t}}(\mathrm{x})=\mathrm{r} \times \mathrm{r}_{\mathrm{u}, \mathrm{t}}
\end{aligned}
$$

In any $\mathrm{t}$, a numerical degree predicate $r$ unit $P$ denotes a predicate true of entities whose degree in $\mathrm{P}$ is $\mathrm{r}$ times the degree of a unit-object in $\mathrm{t}$.

For example, the derivation of the interpretation of Dan is two meters tall is given in (27) below. ${ }^{14}$

\footnotetext{
${ }^{11}$ See Schwarzschild (2005), Brasoveanu (2009), and Bale (2008) for the view that unit nouns in classifier constructions (such as pounds of cheese) can directly refer to the set of unit objects.

12 As argued in Sassoon (2010), the comparability of the dimensions of a unit noun (e.g., tall, wide, long, etc.) follows, e.g. Dan is 2 inches taller than this bed is long is true iff $\mathrm{f}_{\text {tall, } \mathrm{t}}\left(\llbracket\right.$ Dan $\left.\rrbracket_{\mathrm{t}}\right)-\mathrm{f}_{\text {long,t },}(\llbracket$ the bed $\left.\rrbracket_{\mathfrak{t}}\right)=2 \times \mathrm{r}_{\mathrm{i}, \mathrm{t}}$, i.e., the difference between Dan's degree of height and the bed's degree of length equals twice the degree of an inch unit object (the value $\mathrm{f}_{\text {tall, }}$ assigns to its unit objects, which equals the value $\mathrm{f}_{\text {long,t }}$ assigns to its unit objects).

${ }^{13}$ Schwarzschild (2005), Brasoveanu (2009), and Bale (2008) independently support this ambiguity view.

${ }^{14}$ I assume that unit names like meters have an adjectival argument in English (a nominal one in Russian and Hebrew), as the latter specifies the dimension of measurement, e.g., height, width, length, etc. However, unit names with but one measurement dimension need not select for such an argument. For example, the unit grams is uniquely associated with measures of weight; two grams can only be interpreted as twice the weight of a gram unit-object (see also Murphy 2006).
} 


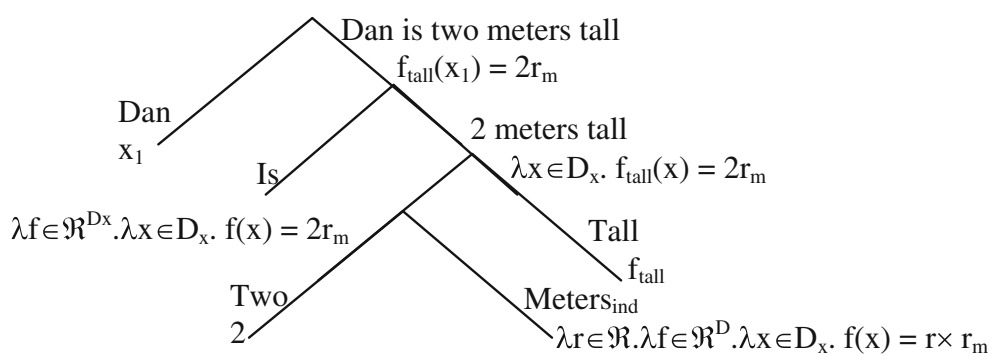

In comparatives, as in, e.g., two meters taller, the adjective tall is an argument of er, not of the unit noun meters, which, therefore, receives its basic, numerical interpretation, as shown in (28).

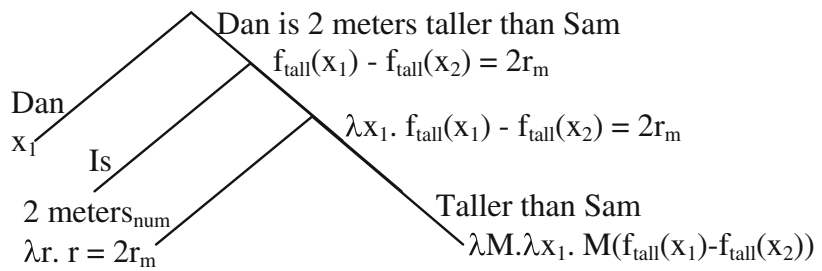

This analysis of unit names presupposes that their semantics involves the application of a ratio operation; e.g. the interpretation of Dan is $r$ inches tall boils down to 'Dan is r times taller than an inch unit-object'. It follows that the distribution of unit names should be restricted to adjectives whose degree functions adequately represent ratios between quantities of the 'stuff' they measure (additive functions). This means that unit names do not combine with transformed adjectives, rendering combinations like inch short uninterpretable. Unit names do combine with adjectives whose degree functions are additive, like tall, rendering combinations like inch tall perfectly interpretable.

Let us first focus on tall. Recall that the height of the ostrich is sixty times the height of the inch in c. The degree function of tall adequately represents this fact given that in every context $\mathrm{t}$ in $\mathrm{T}_{\mathrm{c}}$, tall maps the inch to some number $\mathrm{n}$, and the ostrich to sixty times that number, 60n (cf. (29)). Consequently, The ostrich is sixty inches tall is true in c (cf. (30)).
a. $\mathrm{f}_{\text {tall, } \mathrm{t1} 1}\left(\mathrm{x}_{2}\right)=\mathbf{6 0} \quad \mathrm{f}_{\text {tall,t1 }}\left(\mathrm{x}_{1}\right)=\mathbf{1} \Rightarrow \mathrm{f}_{\text {tall, } \mathrm{t} 1}\left(\mathrm{x}_{2}\right)=60 \times \mathrm{f}_{\text {tall, } \mathrm{t} 1}\left(\mathrm{x}_{1}\right)$
b. $\mathrm{f}_{\text {tall, } \mathrm{t} 2}\left(\mathrm{x}_{2}\right)=\mathbf{1 2 0} \quad \mathrm{f}_{\text {tall,t2 }}\left(\mathrm{x}_{1}\right)=\mathbf{2} \Rightarrow \mathrm{f}_{\text {tall, } \mathrm{t} 2}\left(\mathrm{x}_{2}\right)=60 \times \mathrm{f}_{\text {tall,t2 }}\left(\mathrm{x}_{1}\right)$
c. $\mathrm{f}_{\text {tall, } \mathrm{t} 3}\left(\mathrm{x}_{2}\right)=\mathbf{1 8 0} \quad \mathrm{f}_{\text {tall, } \mathrm{t3}}\left(\mathrm{x}_{1}\right)=\mathbf{3} \Rightarrow \mathrm{f}_{\text {tall, } \mathrm{t} 3}\left(\mathrm{x}_{2}\right)=60 \times \mathrm{f}_{\text {tall, } \mathrm{t3}}\left(\mathrm{x}_{1}\right)$

(30) $\llbracket$ The ostrich is sixty inches tall $\rrbracket_{\mathrm{c}}=1$ iff

$\forall \mathrm{t} \in \mathrm{T}_{\mathrm{c}}$, The ostrich is is sixty inches tall $\rrbracket_{\mathrm{t}}=1 \quad$ iff

$\forall \mathrm{t} \in \mathrm{T}_{\mathrm{c}}, \mathrm{f}_{\mathrm{tall}, \mathrm{t}}\left(\llbracket\right.$ The ostrich $\left.\rrbracket_{\mathrm{t}}\right)=60 \times \mathrm{r}_{\mathrm{i}, \mathrm{t}}$

(s.t. $r_{i, t}$ is the real number $f_{\text {tall,t }}$ assigns to the inch unit-objects) iff

$\forall \mathrm{t} \in \mathrm{T}_{\mathrm{c}}, \mathrm{f}_{\text {tall }, \mathrm{t}}\left(\mathrm{x}_{2}\right)=60 \times \mathrm{f}_{\text {tall }, \mathrm{t}}\left(\mathrm{x}_{1}\right)$ 
The situation is different with short. As its degree function is reversed and transformed by an unspecified value in c, we cannot assume that short is a dimension of meter. In every $\mathrm{t}$ in $\mathrm{T}_{\mathrm{c}}$ in which tall maps the inch unit-object to $\mathrm{r}$ and the ostrich to 60r, short maps the inch unit-object to $\operatorname{Tran}_{\text {short,t }}-\mathrm{r}$ and the ostrich to $\operatorname{Tran}_{\text {short,t }}$ $-60 \mathrm{r}$. But none of these two degrees, $\operatorname{Tran}_{\text {short, } t}-\mathrm{r}$ and $\operatorname{Tran}_{\text {short }, \mathrm{t}}-60 \mathrm{r}$, is sixty times the other, unless $\operatorname{Tran}_{\text {short,t }}=0$ (cf. (31)). Since it is not the case that in every context t the ostrich's degree in short equals sixty times the inch unit-object's degree in short (e.g., in $\mathrm{t}_{1}$ and $\mathrm{t}_{3}$ it doesn't), the statement The ostrich is sixty inches short is not true in c (cf. (32)). And since it is not the case that in every context $\mathrm{t}$ the ostrich's degree in short does not equal sixty times the inch unit-object's degree in short (e.g., in $\mathrm{t}_{2}$ it does), The ostrich is sixty inches short is not false in c (cf. (33)).

$$
\begin{aligned}
& \text { a. } \mathrm{f}_{\text {short }, \mathrm{t} 1}\left(\mathrm{x}_{2}\right)=\operatorname{Tran}_{\text {short }, \mathrm{t} 1}-\mathrm{f}_{\text {tall,t1 } 1}\left(\mathrm{x}_{2}\right)=10-60=\mathbf{5 0} \\
& \mathrm{f}_{\text {short }, \mathrm{t1}}\left(\mathrm{x}_{1}\right)=\operatorname{Tran}_{\text {short } \mathrm{t} 1}-\mathrm{f}_{\text {tall,t1 }}\left(\mathrm{x}_{1}\right)=10-1=9 \quad \Rightarrow \\
& \mathrm{f}_{\text {short,t1 }}\left(\mathrm{x}_{2}\right) \neq 60 \times \mathrm{f}_{\text {short }, \mathrm{t} 1}\left(\mathrm{x}_{1}\right) \\
& \text { b. } \mathrm{f}_{\text {short }, \mathrm{t} 2}\left(\mathrm{x}_{2}\right)=\operatorname{Tran}_{\text {short }, \mathrm{t} 2}-\mathrm{f}_{\text {tall, } \mathrm{t} 2}\left(\mathrm{x}_{2}\right)=0-120=\mathbf{- 1 2 0} \\
& \mathrm{f}_{\text {short }, \mathrm{t} 2}\left(\mathrm{x}_{1}\right)=\operatorname{Tran}_{\text {short,t2 }}-\mathrm{f}_{\text {tall }, \mathrm{t} 2}\left(\mathrm{x}_{1}\right)=0-2 \quad=-2 \quad \Rightarrow \\
& \mathrm{f}_{\text {short }, \mathrm{t} 2}\left(\mathrm{x}_{2}\right)=60 \times \mathrm{f}_{\text {short }, \mathrm{t} 2}\left(\mathrm{x}_{1}\right) \\
& \text { c. } \mathrm{f}_{\text {short }, \mathrm{t} 3}\left(\mathrm{x}_{2}\right)=\operatorname{Tran}_{\text {short }, \mathrm{t} 3}-\mathrm{f}_{\text {tall, } \mathrm{t} 3}\left(\mathrm{x}_{2}\right)=-10-180=-\mathbf{1 9 0} \\
& \mathrm{f}_{\text {short, } \mathrm{t} 3}\left(\mathrm{x}_{1}\right)=\operatorname{Tran}_{\text {short }, \mathrm{t} 3}-\mathrm{f}_{\text {tall, } \mathrm{t} 3}\left(\mathrm{x}_{1}\right)=-10-3=-\mathbf{1 3} \quad \Rightarrow \\
& \mathrm{f}_{\text {short }, \mathrm{t} 3}\left(\mathrm{x}_{2}\right) \neq 60 \times \mathrm{f}_{\text {short }, \mathrm{t} 3}\left(\mathrm{x}_{1}\right)
\end{aligned}
$$

$\llbracket$ The ostrich is sixty inches short $\rrbracket_{\mathrm{c}}=1$

iff

$\forall \mathrm{t} \in \mathrm{T}_{\mathrm{c}}, \llbracket$ The ostrich is sixty inches short $\rrbracket_{\mathrm{t}}=1 \quad$ iff

$\forall \mathrm{t} \in \mathrm{T}_{\mathrm{c}}, \mathrm{f}_{\text {short } \mathrm{t}}\left(\llbracket\right.$ The ostrich $\left.\rrbracket_{\mathrm{t}}\right)=60 \times \mathrm{r}_{\mathrm{i}, \mathrm{t}}$

(s.t. $r_{i, t}$ is the real number $f_{\text {short }, t}$ assigns to the inch unit-objects) iff

$\forall \mathrm{t} \in \mathrm{T}_{\mathrm{c}}, \operatorname{Tran}_{\text {short } \mathrm{t}}-\mathrm{f}_{\text {tall, } \mathrm{t}}\left(\mathrm{x}_{2}\right)=60 \times\left(\operatorname{Tran}_{\text {short }, \mathrm{t}}-\mathrm{f}_{\text {tall, } \mathrm{t}}\left(\mathrm{x}_{1}\right)\right) \quad$ iff

$\forall \mathrm{t} \in \mathrm{T}_{\mathrm{c}}, 60 \times \mathrm{f}_{\text {tall,t }}(\mathrm{x} 1)-\mathrm{f}_{\text {tall, }}\left(\mathrm{x}_{2}\right)=59 \times \operatorname{Tran}_{\text {short }, \mathrm{t}}$

(33) $\llbracket$ The ostrich is sixty inches short $\rrbracket_{\mathrm{c}}=0$

iff

$\forall \mathrm{t} \in \mathrm{T}_{\mathrm{c}}$, $\llbracket$ The ostrich is sixty inches short $\rrbracket_{\mathrm{t}}=0$

iff

$\forall \mathrm{t} \in \mathrm{T}_{\mathrm{c}}, 60 \times \mathrm{f}_{\text {tall, } \mathrm{t}}\left(\mathrm{x}_{1}\right)-\mathrm{f}_{\text {tall, } \mathrm{t}}\left(\mathrm{x}_{2}\right) \neq 59 \times \operatorname{Tran}_{\text {short } \mathrm{t}}$

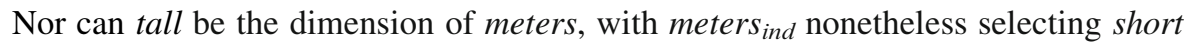
as an argument. In every $\mathrm{t}$ in $\mathrm{T}_{\mathrm{c}}$ in which tall maps the inch unit-object to $\mathrm{r}$ and the ostrich to 60r, short maps the ostrich to $\operatorname{Tran}_{\text {short,t }}-60 \mathrm{r}$. But neither of the two degrees, $r$ and Tran $_{\text {short, } t}-60 r$, is sixty times the other (cf. (34)). Again, it is not the case that in every context $t$ the ostrich's degree in short equals sixty times the inch unit-object's degree in tall (e.g., in $\mathrm{t}_{1}, \mathrm{t}_{2}$, and $\mathrm{t}_{3}$ it doesn't), so the statement The ostrich is sixty inches short is not true in c (cf. (35)). The falsity condition in (36) is actually satisfied in c, but that happens solely because we use a simplified example, with but three indices (three possible transformation values). The falsity condition is violated once a context $t_{4}$ is added which is, say, identical to $t_{1}$ except that the transformation value equals 120 (cf. (37)). In other words, it is generally not the case that in every context t the ostrich's degree in short does not equal sixty times the inch unit-object's degree in short (e.g., in $\mathrm{t}_{4}$ it does). So The ostrich is sixty inches short is not false in contexts c. 

a. $\mathrm{f}_{\text {short }, \mathrm{t} 1}\left(\mathrm{x}_{2}\right)=\operatorname{Tran}_{\text {short }, \mathrm{t} 1}-\mathrm{f}_{\text {tall, } \mathrm{t1}}\left(\mathrm{x}_{2}\right)=10-60=\mathbf{5 0}$
$\mathrm{f}_{\text {tall,t1 }}\left(\mathrm{x}_{1}\right)=1 \quad \Rightarrow \quad \mathrm{f}_{\text {short }, \mathrm{t} 1}\left(\mathrm{x}_{2}\right) \neq 60 \times \mathrm{f}_{\text {tall,t1 }}\left(\mathrm{x}_{1}\right)$
b. $\mathrm{f}_{\text {short }, \mathrm{t} 2}\left(\mathrm{x}_{2}\right)=\operatorname{Tran}_{\text {short }, \mathrm{t} 2}-\mathrm{f}_{\text {tall }, \mathrm{t} 2}\left(\mathrm{x}_{2}\right)=0-120=\mathbf{- 1 2 0}$
$\mathrm{f}_{\text {tall,t } 2}\left(\mathrm{x}_{1}\right)=2 \quad \Rightarrow \quad \mathrm{f}_{\text {short }, \mathrm{t} 2}\left(\mathrm{x}_{2}\right) \neq 60 \times \mathrm{f}_{\mathrm{tall}, \mathrm{t} 2}\left(\mathrm{x}_{1}\right)$
d. $\mathrm{f}_{\text {short }, \mathrm{t} 3}\left(\mathrm{x}_{2}\right)=\operatorname{Tran}_{\text {short }, \mathrm{t} 3}-\mathrm{f}_{\text {tall }, \mathrm{t} 3}\left(\mathrm{x}_{2}\right)=-10-180=\mathbf{- 1 9 0}$
$\mathrm{f}_{\text {tall, } \mathrm{t} 3}\left(\mathrm{x}_{1}\right)=3 \quad \Rightarrow \quad \mathrm{f}_{\text {short }, \mathrm{t} 3}\left(\mathrm{x}_{2}\right) \neq 60 \times \mathrm{f}_{\text {tall, } \mathrm{t} 3}\left(\mathrm{x}_{1}\right)$

(35) $\llbracket$ The ostrich is sixty inches short $\rrbracket_{\mathrm{c}}=1 \quad$ iff

$\forall \mathrm{t} \in \mathrm{T}_{\mathrm{c}}$, 【The ostrich is sixty inches short $\rrbracket_{\mathrm{t}}=1 \quad$ iff

$\forall \mathrm{t} \in \mathrm{T}_{\mathrm{c}}, \mathrm{f}_{\text {short } \mathrm{t}}\left(\llbracket\right.$ The ostrich $\left.\rrbracket_{\mathrm{t}}\right)=60 \times \mathrm{r}_{\mathrm{i}, \mathrm{t}}$

(s.t. $r_{i, t}$ is the real number $f_{\text {tall,t }}$ assigns to the inch unit-objects) iff

$\forall \mathrm{t} \in \mathrm{T}_{\mathrm{c}}, \operatorname{Tran}_{\text {short } \mathrm{t}}-\mathrm{f}_{\mathrm{tall}, \mathrm{t}}\left(\mathrm{x}_{2}\right)=60 \times \mathrm{f}_{\text {tall, } \mathrm{t}}\left(\mathrm{x}_{1}\right) \quad$ iff

$\forall \mathrm{t} \in \mathrm{T}_{\mathrm{c}}, 60 \times \mathrm{f}_{\text {tall, } \mathrm{t}}(\mathrm{x} 1)+\mathrm{f}_{\text {tall,t }}\left(\mathrm{x}_{2}\right)=\operatorname{Tran}_{\text {short }, \mathrm{t}}$

(36) 【The ostrich is sixty inches short $\rrbracket_{\mathrm{c}}=0 \quad$ iff

$\forall \mathrm{t} \in \mathrm{T}_{\mathrm{c}}, \llbracket$ The ostrich is sixty inches short $\rrbracket_{\mathrm{t}}=0$ iff

$\forall \mathrm{t} \in \mathrm{T}_{\mathrm{c}}, \operatorname{Tran}_{\text {short, }}-\mathrm{f}_{\text {tall, } \mathrm{t}}\left(\mathrm{x}_{2}\right) \neq 60 \times \mathrm{f}_{\text {tall, } \mathrm{t}}\left(\mathrm{x}_{1}\right) \quad$ iff

$\forall \mathrm{t} \in \mathrm{T}_{\mathrm{c}}, 60 \times \mathrm{f}_{\text {tall,t }}\left(\mathrm{x}_{1}\right)+\mathrm{f}_{\text {tall,t }}\left(\mathrm{x}_{2}\right) \neq \operatorname{Tran}_{\text {short }, \mathrm{t}}$

(37) $\mathrm{f}_{\text {short,t1 }}\left(\mathrm{x}_{2}\right)=\operatorname{Tran}_{\text {short,t1 }}-\mathrm{f}_{\text {tall, } \mathrm{t} 1}\left(\mathrm{x}_{2}\right)=120-60=\mathbf{6 0}$

$\mathrm{f}_{\text {tall }, \mathrm{t} 1}\left(\mathrm{x}_{1}\right)=1 \Rightarrow \mathrm{f}_{\text {short }, \mathrm{t} 1}\left(\mathrm{x}_{2}\right)=60 \times \mathrm{f}_{\text {tall, } \mathrm{t1}}\left(\mathrm{x}_{1}\right)$

Again, in both the truth conditions and the falsity conditions ((32)-(33), respectively, and (35)-(36), respectively) a meta-language variable occurs, Tran short $_{\text {, }}$ whose value is unspecified in c (varies across $T_{c}$ ), rendering the truth value of such statements inherently undetermined. As this is the situation in every actual context $\mathrm{c}$ in which negative adjectives like short receive their default (reversed and transformed) interpretation, combinations of numerical degree modifiers with negative adjectives are ungrammatical.

To summarize, lacking knowledge about $\operatorname{Tran}_{\text {short }}$, for no number $\mathrm{r}$ can we say which entities are $\mathrm{r}$ inches short in $\mathrm{c}\left(\neg \exists \mathrm{x} \in \mathrm{D}_{\mathrm{x}}: \forall \mathrm{t} \in \mathrm{T}_{\mathrm{c}}, \mathrm{f}_{\text {short, } \mathrm{t}}(\mathrm{x})=\mathrm{r}\right)$. So numerical-degree phrases like two inches cannot be used with short. Therefore, unit names are always interpreted as taking an additive (non-transformed) adjective as an argument, e.g., utterances such as 'two inches' are understood as meaning two inches tall, two inches wide, or two inches long, but never two inches short or two inches narrow. But in statements like, e.g., The ostrich is sixty inches short, the adjectival argument of inches is specified as short. Therefore, we cannot possibly interpret inches as equivalent to inches tall or inches wide. Consequently, the statement is uninterpretable (ungrammatical).

Importantly, while, e.g., two meters short is totally ungrammatical, twice as short is not as bad (as discussed in Sect. 5). The explanation is rather simple. Unlike ratio modifiers, unit names must be conventionally (lexically) linked to a set of adjectives (cf. (24)), all of which must be ones whose degree functions are additive (appropriately encode degree ratios), as illustrated in this section. Thus, speakers won't link unit names to adjectives like short which are predominantly not interpreted as 
additive, despite the existence of ad hoc contexts in which they are so interpreted. However, nothing prevents a twice modification in the ad hoc non-default additive contexts. As a result, while measure phrases are utterly bad with negative adjectives, our grammaticality judgments may almost fail to distinguish between ratio statements with positive and negative adjectives. Still, since ratio modifiers can only combine with negative adjectives in contexts that select for a secondary interpretation, twice is used less often with negative than with positive adjectives, as predicted, and as the distributional patterns discussed in Sects. 5.2-5.3 reveal.

\subsection{Numerical degree modifiers in comparison statements}

The situation is different in the comparative. A numerical degree phrase like two inches $_{\text {num }}$ is perfectly interpretable when combined with comparative adjectives either as a modifier, as in two inches shorter (cf. Sect. 4.3.1), or as an argument, as in shorter than two inches (cf. Sect. 4.3.2).

\subsubsection{Modification of difference comparisons}

Recall our assumption that comparative adjectives express degree differences (cf. Sect. 4.1). For example, comparison statements like The ostrich is taller than the chicken ( $i$ ) hold true in a given context $\mathrm{t}$ iff the difference between the degrees of height in $\mathrm{t}$ of the chicken and of the ostrich is a positive real number.

$$
\begin{array}{lll}
\llbracket \text { The ostrich is taller than the chicken } \rrbracket_{\mathrm{t}}=1 & \text { iff } \\
\mathrm{f}_{\text {tall, } \mathrm{t}}\left(\llbracket \text { The } \text { ostrich } \rrbracket_{\mathrm{t}}\right)-\mathrm{f}_{\text {tall, } \mathrm{t}}\left(\llbracket \text { The chicken } \rrbracket_{\mathrm{t}}\right)>0 & \text { iff } \\
\mathrm{f}_{\text {tall, } \mathrm{t}}\left(\mathrm{x}_{2}\right)-\mathrm{f}_{\text {tall, } \mathrm{t}}\left(\mathrm{x}_{3}\right)>0 &
\end{array}
$$

The present analysis of negative adjectives correctly predicts that derived comparatives of negative adjectives will license numerical degree modifiers (as in The chicken is thirty inches shorter than the ostrich) by virtue of the fact that when degree differences are computed, the transformation values of the two degrees cancel one another.

Again, let us first focus on tall. The difference between the height of the ostrich and the height of the chicken equals exactly thirty times the height of an inch unit object. The degree function of tall adequately represents this fact, given that in every context $t$ in $T_{c}$, the difference between the two degrees tall assigns to the ostrich and the chicken equals exactly thirty times the value tall assigns to an inch unit-object (cf. (39)). Consequently, the statement The ostrich is thirty inches taller than the chicken is true in c (cf. (40)).

$$
\begin{aligned}
& \text { a. } \mathrm{f}_{\text {tall, } \mathrm{t} 1}\left(\mathrm{x}_{2}\right)-\mathrm{f}_{\text {tall,t1 }}\left(\mathrm{x}_{3}\right)=60-30=\mathbf{3 0} \\
& \text { b. } \mathrm{f}_{\text {tall, }, \mathrm{t} 2}\left(\mathrm{x}_{2}\right)-\mathrm{f}_{\text {tall,t2 }}\left(\mathrm{x}_{3}\right)=120-60=\mathbf{6 0} \\
& \mathrm{f}_{\mathrm{tall}, \mathrm{t} 1}\left(\mathrm{x}_{1}\right)=\mathbf{1} \\
& \text { c. } \mathrm{f}_{\text {tall, }, 3}\left(\mathrm{x}_{2}\right)-\mathrm{f}_{\text {tall, } \mathrm{t} 3}\left(\mathrm{x}_{3}\right)=180-90=\mathbf{9 0} \\
& \mathrm{f}_{\text {tall, } \mathrm{t} 2}\left(\mathrm{x}_{1}\right)=\mathbf{2} \\
& \text { d. } \Rightarrow \forall \mathrm{t} \in \mathrm{T}_{\mathrm{c}}: \mathrm{f}_{\text {tall, } \mathrm{t}}\left(\mathrm{x}_{2}\right)-\mathrm{f}_{\text {tall,t }}\left(\mathrm{x}_{3}\right)=30 \times \mathrm{f}_{\text {tall, } \mathrm{t}}\left(\mathrm{x}_{1}\right)
\end{aligned}
$$

(40) $\llbracket$ The ostrich is thirty inches taller than the chicken $\rrbracket_{\mathrm{t}}=1$ iff $\mathrm{f}_{\text {tall, } \mathrm{t}}\left(\llbracket\right.$ The ostrich $\left.\rrbracket_{\mathrm{t}}\right)-\mathrm{f}_{\text {tall, } \mathrm{t}}\left(\llbracket\right.$ The chicken $\left.\rrbracket_{\mathrm{t}}\right)=30 \times \mathrm{r}_{\mathrm{i}, \mathrm{t}} \quad$ iff $\mathrm{f}_{\text {tall,t }}\left(\mathrm{x}_{2}\right)-\mathrm{f}_{\text {tall, } \mathrm{t}}\left(\mathrm{x}_{3}\right)=30 \times \mathrm{f}_{\text {tall, } \mathrm{t}}\left(\mathrm{x}_{1}\right)$ 
Interestingly, the degree function of short also adequately represents the given height difference. This happens by virtue of the fact that when degree differences are computed, the transformation values of the two degrees cancel one another, leaving an untransformed value which, as we have just demonstrated, is equal to exactly thirty times the value tall assigns to an inch unit-object (cf. (41)). In any t the difference between the two degrees short assigns to the chicken and the ostrich equals exactly thirty times the value tall assigns to an inch unit-object, so The chicken is thirty inches shorter than the ostrich (is) is true in c (cf. (42)). ${ }^{15}$
a. $\mathrm{f}_{\text {short }, \mathrm{t} 1}\left(\mathrm{x}_{3}\right)-\mathrm{f}_{\text {short }, \mathrm{t} 1}\left(\mathrm{x}_{2}\right)=\left(\operatorname{Tran}_{\text {short }, \mathrm{t} 1}-\mathrm{f}_{\text {tall }, \mathrm{t} 1}\left(\mathrm{x}_{3}\right)\right)-\left(\operatorname{Tran}_{\text {short }, \mathrm{t} 1}-\mathrm{f}_{\text {tall, } \mathrm{t} 1}\left(\mathrm{x}_{2}\right)\right)$ $=\mathrm{f}_{\text {tall,t1 }}\left(\mathrm{x}_{2}\right)-\mathrm{f}_{\text {tall,t1 }}\left(\mathrm{x}_{3}\right)=60-30=\mathbf{3 0}$ $\mathrm{f}_{\text {tall, } \mathrm{t} 1}\left(\mathrm{x}_{1}\right)=1$
b. $\mathrm{f}_{\text {short }, \mathrm{t} 2}\left(\mathrm{x}_{3}\right)-\mathrm{f}_{\text {short }, \mathrm{t} 2}\left(\mathrm{x}_{2}\right)=\left(\operatorname{Tram}_{\text {short }, \mathrm{t} 2}-\mathrm{f}_{\text {tall, } \mathrm{t} 2}\left(\mathrm{x}_{3}\right)\right)-\left(\operatorname{Tram}_{\text {short }, \mathrm{t} 2}-\mathrm{f}_{\text {tall, t2 }}\left(\mathrm{x}_{2}\right)\right)$ $=\mathrm{f}_{\text {tall,t2 }}\left(\mathrm{x}_{2}\right)-\mathrm{f}_{\text {tall,t2 }}\left(\mathrm{x}_{3}\right)=120-60=\mathbf{6 0}$ $\mathrm{f}_{\text {tall, } \mathrm{t} 2}\left(\mathrm{x}_{1}\right)=2$
c. $\mathrm{f}_{\text {short }, \mathrm{t} 3}\left(\mathrm{x}_{3}\right)-\mathrm{f}_{\text {short }, \mathrm{t} 3}\left(\mathrm{x}_{2}\right)=\left(\operatorname{Tram}_{\text {short }, \mathrm{t} 3}-\mathrm{f}_{\text {tall, } \mathrm{t} 3}\left(\mathrm{x}_{3}\right)\right)-\left(\operatorname{Tram}_{\text {short }, \mathrm{t} 3}-\mathrm{f}_{\text {tall,t3 }}\left(\mathrm{x}_{2}\right)\right)$ $=\mathrm{f}_{\text {tall, }, \mathrm{t} 3}\left(\mathrm{x}_{2}\right)-\mathrm{f}_{\text {tall, } \mathrm{t} 3}\left(\mathrm{x}_{3}\right)=180-90=\mathbf{9 0}$ $\mathrm{f}_{\text {tall, }, \mathrm{t} 3}\left(\mathrm{x}_{1}\right)=\mathbf{3}$

(42) 【The chicken is thirty inches shorter than the ostrich $\rrbracket_{\mathrm{t}}=1 \quad$ iff $\mathrm{f}_{\text {short }, \mathrm{t}}\left(\llbracket\right.$ The chicken $\left.\rrbracket_{\mathrm{t}}\right)-\mathrm{f}_{\text {short }, \mathrm{t}}\left(\llbracket\right.$ The ostrich $\left.\rrbracket_{\mathrm{t}}\right)=30 \times \mathrm{r}_{\mathrm{i}, \mathrm{t}}$ (s.t. $r_{i, t}$ is the real number $f_{\text {tall,t }}$ assigns to the inch unit-objects) $\left(\right.$ Tran $_{\text {short }, \mathrm{t}}-\mathrm{f}_{\text {tall, }, \mathrm{t}}\left(\llbracket\right.$ The chicken $\left.\rrbracket_{\mathrm{t}}\right)-\left(\right.$ Tran $_{\text {short }, \mathrm{t}}-\mathrm{f}_{\text {tall, }, \mathrm{t}}\left(\llbracket\right.$ The ostrich $\left.\rrbracket_{\mathrm{t}}\right)=30 \mathrm{r}_{\mathrm{i}, \mathrm{t}}$ iff $\mathrm{f}_{\text {tall, } \mathrm{t}}\left(\llbracket\right.$ The ostrich $\left.\rrbracket_{\mathrm{t}}\right)-\mathrm{f}_{\text {tall, } \mathrm{t}}\left(\llbracket\right.$ The chicken $\left.\rrbracket_{\mathrm{t}}\right)=30 \times \mathrm{r}_{\mathrm{i}, \mathrm{t}} \quad$ iff $\mathrm{f}_{\text {tall, } \mathrm{t}}\left(\mathrm{x}_{2}\right)-\mathrm{f}_{\text {tall }, \mathrm{t}}\left(\mathrm{x}_{3}\right)=30 \times \mathrm{f}_{\text {tall, } \mathrm{t}}\left(\mathrm{x}_{1}\right)$

So the present analysis correctly predicts that numerical degree predicates are felicitous as modifiers of both positive and negative comparative adjectives. ${ }^{16}$

\subsubsection{Numerical degree modifiers in object position}

What about numerical degree modifiers in object position, as in Dan is taller than two meters? I analyze phrases like two meters as predicates, not degree terms. Thus, in object position, we have a mismatch that can be resolved by type-lifting the interpretation of two meters ind $_{\text {(i.e., }} \lambda \mathrm{x} \in \mathrm{D}_{\mathrm{x}} \cdot \mathrm{f}_{\mathrm{tall}}(\mathrm{x})=2 \mathrm{r}_{\mathrm{m}, \mathrm{t}}$ ) to a generalized quantifier meaning (the type of two doctors in Dan kissed two doctors), i.e. to $\lambda \mathrm{M} . \exists \mathrm{x}, \llbracket$ two meters tall $\rrbracket_{\mathrm{t}}(\mathrm{x}): \mathrm{M}(\mathrm{x})$ (which reduces to $\lambda \mathrm{M} . \exists \mathrm{x}, \mathrm{f}_{\mathrm{tall}}(\mathrm{x})=2 \mathrm{r}_{\mathrm{m}, \mathrm{t}}: \mathrm{M}(\mathrm{x})$ ), and type-lifting the interpretation of taller $\left(\lambda \mathrm{x}_{2} \cdot \lambda \mathrm{M} \cdot \lambda \mathrm{x}_{1} \cdot \mathrm{M}\left(\mathrm{f}_{\text {tall }}\left(\mathrm{x}_{1}\right)-\mathrm{f}_{\text {tall }}\left(\mathrm{x}_{2}\right)\right)\right)$ accordingly, to $\lambda \mathrm{GQ} \cdot \lambda \mathrm{M} \cdot \lambda \mathrm{x}_{1} \cdot \mathrm{GQ}\left(\lambda \mathrm{x}_{2} \cdot \mathrm{M}\left(\mathrm{f}_{\text {tall }}\left(\mathrm{x}_{1}\right)-\mathrm{f}\left(\mathrm{x}_{2}\right)\right)\right)$. The derivation of Dan is taller than two meters is illustrated in (43) below.

\footnotetext{
15 Recall that in thirty inches shorter, the predicate short does not function as the argument of inches (but as the argument of er), so thirty inches is interpretable.

16 The root of the idea that in comparison predicates a transformation value is set up to zero, so to speak, is already present in Kennedy and McNally (2005), Svenonious and Kennedy (2006), and Winter (2005).
} 
(43)

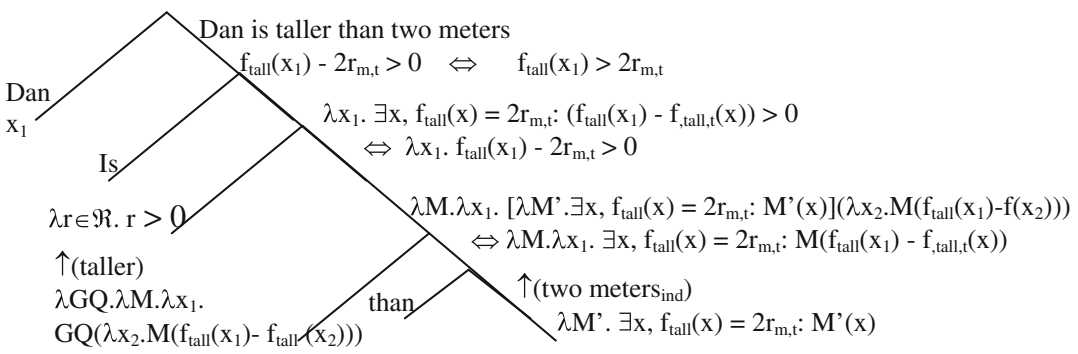

On this standard solution to this type mismatch, a sentence such as Dan is shorter than two meters is analyzed as 'Dan is shorter than [something that is] two meters'; i.e., the difference between the degree to which Dan is short and the degree to which something - anything whose height is twice the height of a meter-is short is a positive real number (I leave it to the reader to verify this with a derivation). So the sentence is predicted to be interpretable (unlike, e.g., Dan is two meters short), and the interpretation is intuitively the right one. ${ }^{17}$

\subsection{Cross-polar anomalies}

For the analysis of cross-polar comparisons, consider the following simplified analysis of clausal er, whereby it resembles phrasal er except that its internal argument is a generalized quantifier (type $\langle\langle\mathrm{r}, \mathrm{t}\rangle, \mathrm{t}\rangle$ ) rather than a number type $\mathrm{r}$ (this is to capture the so-called wide-scope readings of conjunctive quantifiers in thanclauses; cf. Schwarzschild and Wilkinson 2002; Heim 2006a).

$$
\llbracket \text { er than } \rrbracket_{\mathrm{t}}=\lambda \mathrm{GQ} \cdot \lambda \mathrm{M} \cdot \lambda \mathrm{f} \lambda \mathrm{x}_{1} \cdot \mathrm{GQ}\left(\lambda \mathrm{r}_{2} \cdot \mathrm{M}\left(\mathrm{f}\left(\mathrm{x}_{1}\right)-\mathrm{r}_{2}\right)\right)
$$

In accordance with (44), I represent than-clauses as generalized quantifiers - that is, I do not interpret than Sam is tall as $\mathrm{f}_{\text {tall, } \mathrm{t}}(\llbracket \mathrm{Sam} \rrbracket)$, but rather as $\lambda \mathrm{M}_{\langle\mathrm{r}, \mathrm{t}\rangle} \cdot \mathrm{M}\left(\mathrm{f}_{\text {tall,t }}\right.$ $\left.\left(\llbracket \operatorname{Sam} \rrbracket_{t}\right)\right)$, namely, a function from degree predicates $M$ into truth value 1 iff Sam's height is $\mathrm{M}$. This is precisely the interpretation type of than every boy is: $\lambda \mathrm{M} . \llbracket$ boy $\rrbracket_{\mathrm{t}} \subseteq \lambda \mathrm{x} \in \mathrm{D}_{\mathrm{x}} \cdot \mathrm{M}\left(\mathrm{f}_{\text {tall, }}(\mathrm{x})\right)$, namely, a function from degree predicates $\mathrm{M}$ into truth value 1 iff every boy's height is M. ${ }^{18}$ Also, I follow Bresnan (1973) in assuming that if the content of the than-clause predicate is recoverable (via identity

\footnotetext{
${ }^{17}$ Note that the negative polarity of short should not be blamed for the infelicity of, for example, \#Dan is as short as two meters, as the corresponding equative with tall is just as bad (\#Dan is as tall as two meters). Measure phrases are odd also in object position of clausal comparatives (e.g., \#Dan is taller/ shorter than two meters is/are), presumably because clausal comparatives often reinforce distributive 'wide-scope' readings (e.g., Dan is taller than every boy is considered true iff every boy is such that Dan is taller than him; similarly, Dan is taller than two meters are is interpreted as true iff Dan is taller than each one of some two meters).

18 This is compatible with standard analyses of than-clauses (Bresnan 1973; Creswell 1976; Heim 2000, 2001), whereby a silent WH operator moves, leaving a trace M at the AP specifier (called DegP) to be bound by a lambda operator at the embedded CP level (Heim and Kratzer 1998). However, M is usually taken to be of the type of degree terms, and so $e r$ is analyzed as a determiner over degree predicates (the matrix clause is analyzed as a degree predicate, based on the assumption that the whole er-phrase moves at LF, leaving a trace at the specifier of the main clause's AP, to be bound by a lambda operator; Heim 2000, 2001).
} 
with the matrix clause predicate), it is obligatorily deleted. The derivation of Dan is two meters taller than Sam is illustrated in (45).

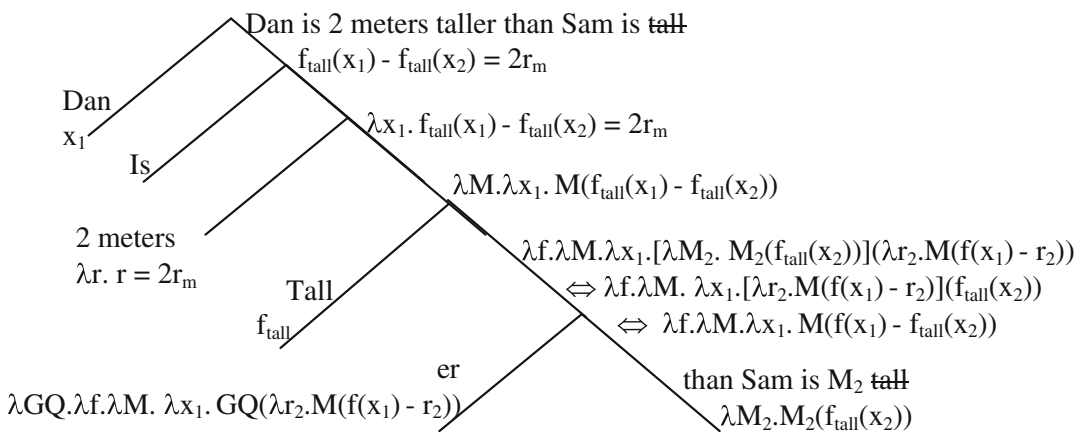

Why are cross-polar comparisons like *The chicken is taller than the ostrich is short infelicitous? For the statement to hold true the difference between the degree which tall assigns to the chicken and the degree which short assigns to the ostrich should be a positive real number:

$\llbracket$ The chicken is taller than the ostrich is short $\rrbracket_{\mathrm{t}}=1 \quad$ iff

$\mathrm{f}_{\text {tall, } \mathrm{t}}\left(\llbracket\right.$ The chicken $\left.\rrbracket_{\mathrm{t}}\right)-\left(\operatorname{Tran}_{\text {short, } \mathrm{t}}-\mathrm{f}_{\text {tall, } \mathrm{t}}\left(\llbracket\right.\right.$ The ostrich $\left.\left.\rrbracket_{\mathrm{t}}\right)\right)>0$ iff

$\mathrm{f}_{\text {tall, } \mathrm{t}}\left(\llbracket\right.$ The chicken $\left.\rrbracket_{\mathrm{t}}\right)+\mathrm{f}_{\text {tall, } \mathrm{t}}\left(\llbracket\right.$ The ostrich $\left.\rrbracket_{\mathrm{t}}\right)-\operatorname{Tran}_{\text {short }, \mathrm{t}}>0$

Since only the degree assigned by short $\left(\operatorname{Tran}_{\text {short,t }}-\mathrm{f}_{\text {tall,t }}\left(\llbracket\right.\right.$ The ostrich $\left.\left.\rrbracket_{\mathrm{t}}\right)\right)$ introduces a transformation-value variable, this variable is not canceled out. As its value is unspecified in c, we cannot tell whether the degree difference is a positive number or not; for example, in $\mathrm{t}_{1}$ it is positive, but in $\mathrm{t}_{4}$ (a completion in all respects identical to $t_{1}$, except that the transformation value equals 120 rather than 10 ) it is not positive.

$$
\mathrm{f}_{\text {tall,t1 }}\left(\mathrm{x}_{3}\right)-\mathrm{f}_{\text {short,t1 }}\left(\mathrm{x}_{2}\right)=30-\left(\operatorname{Tran}_{\text {short,t1 }}-60\right)=90-\operatorname{Tran}_{\text {short }, \mathrm{t} 1}
$$

Consequently, cross-polar comparisons (such as *The ostrich is taller than the chicken is short) can never be verified or falsified and are, therefore, considered anomalies.

Finally, cross-polar comparisons are perfectly fine when a negative adjective is in the matrix clause and the positive counterpart in the than-clause is not its direct antonym, as in, e.g., The ladder is shorter than the gap is wide (Landman 2005; Büring 2007). For reasons of space, I cannot pursue a proper analysis of cross-polar nomalies. However, it is important to notice that in such examples we actually compare two negative degrees; for instance, according to Büring (2007) and Heim (2008), in the above example, we compare the degree of shortness of the ladder with the degree of narrowness of the gap. Thus, these comparisons are not truly crosspolar. Consequently, rather than forming counterexamples to my proposal, they lend additional support to it, at least in that the impossibility of interpreting a difference 
comparison with one reversed and one non-reversed degree forces us into an interpretation with two reversed degrees (and two transformation values), despite the presence of two antonyms, a negative and a positive one. ${ }^{19}$

To conclude Sect. 4, the main linguistic contrasts characterizing paradigmatic antonym pairs follow directly from the present analysis. Having established that, we can now move on to explore non-paradigmatic antonym pairs, as well as additional features of negative and positive antonyms in general.

\section{Non-paradigmatic antonym pairs}

\subsection{A taxonomy of adjective types}

The present proposal clearly distinguishes between function reversal (namely, the use of functions that are linearly reversed in comparison with the base function) and linear transformation (namely, the displacement of the zero compared to the base function, as explained in Sect. 3.2). The use of this distinction can be stated as follows:

(48) +/-Reversal determines the polarity of an adjective:

a. The degree functions of positive adjectives are based on conventional or perceptual measures. They are not reversed with respect to these measures.

b. The degree functions of negative adjectives are reversed in comparison with the degree functions of their positive antonyms. In the absence of a completely specified rule of reversal and in an attempt to avoid negative values, by default these functions are transformed by an unspecified value.

(49) +/-Transformation determines the licensing of numerical degree modifiers:

a. Adjectives whose degree functions are directly based on some additive measuring system license numerical degree modifiers.

b. Adjectives whose degree functions are transformed in comparison with an additive measuring system do not license numerical degree modifiers.

This proposal distinguishes between the four groups of functions in (50) below. As established so far, the interpretations of positive and negative antonyms in paradigmatic pairs pattern with the function types (50a) and (50b) below, respectively. In addition, nothing in the proposals summarized above prevents positive adjectives from being transformed. To the contrary, Sect. 5.3 supports the hypothesis that many positive adjectives ('non-paradigmatic' ones) are indeed interpreted as transformed, i.e., pattern with (50c). Linear transformation regularly affects adjectival interpretations, as suggested by the definitions in (14) above.

\footnotetext{
19 Future research should explicate the mechanism responsible for the reversal of the interpretation of wide and the specification of a transformation value identical to that of short.
} 
Adjectival taxonomy by function type

a. Non-reversed and non-transformed, e.g., $\quad \lambda x \in D_{x} \cdot f_{\text {tall, } t}(x)-0$

b. Reversed and transformed, e.g., $\quad \lambda \mathrm{x} \in \mathrm{D}_{\mathrm{x}} .1-\mathrm{f}_{\text {tall,t }}(\mathrm{x})$

c. Non-reversed and transformed, e.g., $\quad \lambda \mathrm{x} \in \mathrm{D}_{\mathrm{x}} \cdot \mathrm{f}_{\text {tall, } \mathrm{t}}(\mathrm{x})-1$

d. Reversed and non-transformed. e.g., $\quad \lambda \mathrm{x} \in \mathrm{D}_{\mathrm{x}} .0-\mathrm{f}_{\text {tall, }}(\mathrm{x})$

In a sharp contrast, if the present theory of negative antonymy is comprehensive, negative adjectives should not pattern with (50d). Like their paradigmatic counterparts, negative adjectives in non-paradigmatic pairs should also denote reversed and transformed functions. Other interpretations (non-reversed or non-transformed) must remain secondary (rare in $\mathrm{T}_{\mathrm{c}}$ ).

\section{Comprehensive rule of negative antonymy}

An adjective $\mathrm{B}$ is 'negative' in $\mathrm{c}$ iff in $\mathrm{T}_{\mathrm{c}}$ it is predominantly interpreted as reversed, and as a result transformed, such that in nearly all the completions $\mathrm{t}$ in $\mathrm{T}_{\mathrm{c}}, \mathrm{f}_{\mathrm{B}, \mathrm{t}}=\lambda \mathrm{x} \in \mathrm{D}_{\mathrm{x}} \cdot \operatorname{Tran}_{\mathrm{B}, \mathrm{t}}-f(\mathrm{~B}, \mathrm{t})(\mathrm{x})$.

Let us call the converse rule, whereby non-paradigmatic negative antonyms may be predominantly reversed but not transformed, the narrow rule of negative antonymy. According to the narrow rule, adjectives may be predominantly associated with functions of all the four types of the taxonomy in (50), including (50d). The following sections show that reversal and transformation are wide-ranging, supporting the comprehensive rule.

\subsection{Distributional differences between positive and negative adjectives}

The tests presented in Sect. 2 to distinguish positive and negative adjectives are insufficient. Sometimes it is hard to determine which adjective is the positive antonym in a pair. This is likely to happen in the following circumstances.

(i) The adjectives are associated with no conventional measure phrases, or both the negative and the positive antonym fail to license measure phrases, except in the comparative. For example, it is somewhat awkward to say that Yesterday was thirty degrees warm, though it is perfectly acceptable to say that Yesterday was thirty degrees warmer than today (Kennedy 2001). So in terms of the licensing of numerical degree modifiers, warm resembles its negative antonym cold and not other positive adjectives.

(ii) Felicity contrasts between ratio statements with the two given antonyms are hardly felt (as in, e.g., twice as bald versus twice as hairy). ${ }^{20}$

(iii) In the absence of an indirect antonym, the cross-polar (a)nomaly test fails. For example, dirty and clean are direct antonyms, and it is hardly possible to find a related but more indirect antonym comparable with either. ${ }^{21}$

\footnotetext{
${ }^{20}$ Recall that the tests in Sect. 2 only state that "negative adjectives cannot combine with measure phrases/ ratio modifiers, while positive adjectives sometimes do."

21 Recall that this test (Büring 2007) states that cross-polar comparisons are possible with a negative adjective in the matrix clause and a positive indirect antonym in the than-clause (e.g., The ladder is shorter than the gap is wide is fine, although \#The gap is wider than the ladder is short is not).
} 
Thus, sometimes positive adjectives resemble negative ones in crucial respects. This section attempts to provide an additional test for the polarity of adjectives, and to give a firmer basis to the claim that ratio modifiers are generally more compatible with positive adjectives than with negative ones. To this end, I present a corpus study of distributional differences between positive and negative adjectives. The main findings are that, generally, the ratio modifier twice is used significantly more often with positive adjectives than with their negative antonyms. The converse pattern occurs virtually only when twice is relatively rare with both antonyms (cf. Sect. 5.3). The rare exceptions (two negative adjectives that license twice relatively frequently) are discussed in Sect. 5.4.

Ratio modifiers are not used frequently enough for us to be able to assess significant data from linguistic corpuses. For instance, for twice as good as, I have found only 8 results in the British National Corpus (BNC; 100 million words, 19801993, collected by Mark Davies, Brigham Young University), and only 15 results in the corpus of Contemporary American English (360 million words, 1990-2007, also collected by Mark Davies). When searching with Google the results are substantial (e.g., an estimated 196,000 results for twice as good as), but there is a problem of reliability (usage of non-native speakers, duplicates and quotations, possible effects of Google's specific searching criteria, removed entries, etc.) However, even with these caveats, it appears that the tendency observed in our intuitive judgments concerning ratio statements (e.g., (3)-(4) above) finds expression in the estimated Google results for a large number of adjectives. ${ }^{22}$

I Google-searched for 50 antonym pairs (100 adjectives). Some pairs are incompatible with ratio modifiers in both the negative and the positive form (examples include the adjectives typical, atypical, official, unofficial, honest, and dishonest). For 23 of these pairs I found estimates of fewer than 1,000 results which, considering the size of the corpus, is a very small number; considering the range of artifacts, the differences between positive and negative adjectives in these pairs are not informative. The other 27 pairs yielded the results in Table 3.

Blocks 1 and 2 of Table 3 present the number of ratio comparisons (entries of the form twice as $A D J$ as) and equative comparisons (entries of the form as ADJ as), with positive and negative antonyms in the 27 remaining pairs, as well as the ratio between these numbers. ${ }^{23}$

The number of equative comparisons is generally greater in positive adjectives than in their negative antonyms (cf. rows B and D in Table 3). Given studies of children's performance (Gobbo and Agnoli 1985), and brain responses (Molfese 1985), we can presume that this is due to an additional load in the processing of negative adjectives (see also Horn 1989, as well as Giora 2006 and other papers in the same volume). For this reason, instead of directly comparing the number of ratio comparisons in positive adjectives and their negative antonyms (rows $\mathrm{A}$ and $\mathrm{C}$ in Table 3), I first calculated the proportion of ratio comparisons out of the total

\footnotetext{
${ }^{22}$ Also, Lapata and Keller (2005) demonstrate that Google-based counts correlate with frequencies obtained from a carefully edited, balanced corpus such as the BNC, and they reliably predict speakers' judgments.

${ }^{23}$ All searched items were put in quotation marks (as in: "twice as tall as"). The searches were all conducted on the same day, within the same two-hour frame.
} 
number of equative comparisons for each adjective (rows $A / B$ and $C / D$ in Table 3 ), thereby factoring out the processing effect on the frequency of use.

Table 3 The use of twice with adjectives and their antonyms (estimated Google results for each phrase)

I. More uses with the positive adjective, in comparison with the negative antonym (A/B $>C / D)$

\begin{tabular}{|c|c|c|c|c|c|c|c|c|}
\hline & & A & B & $\mathrm{C}$ & $\mathrm{D}$ & $\mathrm{A} / \mathrm{B}$ & $\mathrm{C} / \mathrm{D}$ & $\begin{array}{l}\frac{\mathrm{B})}{\mathrm{C} / \mathrm{D})} \\
\%)\end{array}$ \\
\hline & & $\begin{array}{l}\text { twice as } \\
\text { pos as }\end{array}$ & as pos as & $\begin{array}{l}\text { twice } \\
\text { as neg } \\
\text { as }\end{array}$ & as neg as & $\begin{array}{l}\text { twice as } \\
\text { pos as } \\
\text { as pos as } \\
(\%)\end{array}$ & $\begin{array}{l}\text { twice as } \\
\frac{\text { neg as }}{\text { as neg as }} \\
(\%)\end{array}$ & \\
\hline likely & unlikely & 566,000 & $1,590,000$ & 214 & 196,000 & 35.5975 & 0.1092 & 100 \\
\hline smart & foolish & 15,500 & $1,320,000$ & 6 & 133,000 & 1.1742 & 0.0045 & 100 \\
\hline frequent & rare & 25,500 & 327,000 & 273 & 616,000 & 7.7982 & 0.0443 & 99 \\
\hline tall & short & 90,500 & $1,880,000$ & 934 & $3,240,000$ & 4.8138 & 0.0288 & 99 \\
\hline intelligent & foolish & 1,860 & 309,000 & 6 & 133,000 & 0.6019 & 0.0045 & 99 \\
\hline wide & narrow & 209,000 & $2,570,000$ & 420 & 593,000 & 8.1323 & 0.0708 & 99 \\
\hline strong & weak & 143,000 & $6,140,000$ & 141 & 412,000 & 2.3290 & 0.0342 & 99 \\
\hline long & short & 323,000 & $23,300,000$ & 934 & $3,240,000$ & 1.3863 & 0.0288 & 98 \\
\hline old & young & 75,200 & $4,990,000$ & 1,750 & $3,810,000$ & 1.5070 & 0.0459 & 97 \\
\hline old & new & 75,200 & $4,990,000$ & 184 & 381,000 & 1.5070 & 0.0483 & 97 \\
\hline deep & shallow & 44,300 & $2,130,000$ & 206 & 275,000 & 2.0798 & 0.0749 & 97 \\
\hline dirty & clean & 1,680 & 212,000 & 639 & $1,200,000$ & 0.7925 & 0.0533 & 94 \\
\hline big & small & 191,000 & $7,230,000$ & 20,700 & $6,670,000$ & 2.6418 & 0.3103 & 90 \\
\hline happy & sad & 2,880 & $1,860,000$ & 154 & 471,000 & 0.1548 & 0.0327 & 83 \\
\hline rich & poor & 13,600 & 547,000 & 1,100 & 169,000 & 2.4863 & 0.6509 & 79 \\
\hline smart & stupid & 15,500 & $1,320,000$ & 3,370 & $1,080,000$ & 1.1742 & 0.3120 & 79 \\
\hline intelligent & stupid & 1,860 & 309,000 & 3,370 & $1,080,000$ & 0.6019 & 0.3120 & 66 \\
\hline fast & slow & $1,440,000$ & $19,000,000$ & 31,700 & 787,000 & 7.5789 & 4.0280 & 65 \\
\hline hot & cold & 22,200 & $1,790,000$ & 7,910 & $1,050,000$ & 1.2402 & 0.7533 & 62 \\
\hline happy & unhappy & 2,880 & $1,860,000$ & 65 & 52,600 & 0.1548 & 0.1236 & 56 \\
\hline warm & cold & 5,160 & 565,000 & 7,910 & $1,050,000$ & 0.9133 & 0.7533 & 55 \\
\hline \multicolumn{2}{|l|}{ Average } & 155,515 & $4,011,381$ & 3,904 & $1,268,505$ & 4.03 & 0.37 & 86 \\
\hline
\end{tabular}

II. Fewer uses with the positive adjective, in comparison with the negative antonym (A/B < C/D)

\begin{tabular}{|c|c|c|c|c|c|c|c|c|}
\hline & & $\mathrm{A}$ & B & $\mathrm{C}$ & $\mathrm{D}$ & $\mathrm{A} / \mathrm{B}$ & $\mathrm{C} / \mathrm{D}$ & $\begin{array}{l}\frac{\mathrm{A} / \mathrm{B})}{3+\mathrm{C} / \mathrm{D})} \\
(\%)\end{array}$ \\
\hline & & $\begin{array}{l}\text { twice as } \\
\text { pos as }\end{array}$ & as pos as & $\begin{array}{l}\text { twice } \\
\text { as neg } \\
\text { as }\end{array}$ & as neg as & $\begin{array}{l}\text { twice as } \\
\frac{\text { pos as }}{\text { as pos as }} \\
(\%)\end{array}$ & $\begin{array}{l}\text { twice as } \\
\frac{\text { neg as }}{\text { as neg as }} \\
(\%)\end{array}$ & \\
\hline good & bad & 196,000 & $6,400,000$ & 103,000 & 1,630000 & 3.0625 & 6.3190 & 67 \\
\hline wise & stupid & 235 & 197,000 & 3,370 & 1,080000 & 0.1193 & 0.3120 & 72 \\
\hline healthy & sick & 193 & 764,000 & 1,420 & 283,000 & 0.0253 & 0.5018 & 95 \\
\hline late & early & 56 & $4,120,000$ & 5,880 & 4,280000 & 0.0014 & 0.1374 & 99 \\
\hline
\end{tabular}


Table 3 continued

\begin{tabular}{|c|c|c|c|c|c|c|c|c|}
\hline & & $\mathrm{A}$ & B & $\mathrm{C}$ & $\mathrm{D}$ & $\mathrm{A} / \mathrm{B}$ & $\mathrm{C} / \mathrm{D}$ & $\frac{(\mathrm{A} / \mathrm{B})}{(\mathrm{A} / \mathrm{B}+\mathrm{C} / \mathrm{D})} \underset{(\%)}{ }$ \\
\hline & & $\begin{array}{l}\text { twice as } \\
\text { pos as }\end{array}$ & as pos as & $\begin{array}{l}\text { twice } \\
\text { as neg } \\
\text { as }\end{array}$ & as neg as & $\begin{array}{l}\text { twice as } \\
\frac{\text { pos as }}{\text { as pos as }} \\
(\%)\end{array}$ & $\begin{array}{l}\text { twice as } \\
\frac{\text { neg as }}{\text { as neg as }} \\
(\%)\end{array}$ & \\
\hline right & wrong & 6 & 171,000 & 2,510 & 289,000 & 0.0035 & 0.8685 & 100 \\
\hline quick & slow & 798 & $19,100,000$ & 31,700 & 787,000 & 0.0042 & 4.0280 & 100 \\
\hline Average & & 32,881 & $5,125,333$ & 24,647 & $1,391,500$ & 0.54 & 2.03 & 89 \\
\hline
\end{tabular}

III. Less than 1000 uses with both the positive and the negative adjective

\begin{tabular}{llllllll}
\hline & & $\begin{array}{l}\text { twice as } \\
\text { pos as }\end{array}$ & $\begin{array}{l}\text { twice as } \\
\text { neg as }\end{array}$ & & & $\begin{array}{l}\text { twice as } \\
\text { pos as }\end{array}$ & $\begin{array}{l}\text { twice as } \\
\text { neg as }\end{array}$ \\
\hline similar & different & 738 & 13 & opaque & transparent & 108 & 253 \\
similar & dissimilar & 738 & 1 & full & empty & 38 & 2 \\
relaxed & nervous & 679 & 30 & open & closed & 37 & 1 \\
safe & dangerous & 679 & 542 & honest & dishonest & 8 & 4 \\
safe & unsafe & 679 & 63 & normal & abnormal & 7 & 3 \\
beautiful & ugly & 552 & 556 & possible & impossible & 6 & 1 \\
probable & improbable & 510 & 3 & certain & uncertain & 6 & 64 \\
wet & dry & 480 & 357 & calm & angry & 3 & 347 \\
hairy & bald & 273 & 2 & glad & sad & 2 & 155 \\
easy & difficult & 270 & 673 & necessary & unnecessary & 0 & 2 \\
true & false & 248 & 1 & typical & atypical & 0 & 0 \\
wise & foolish & 237 & 7 & official & unofficial & 0 & 0 \\
wonderful & awful & 163 & 18 & Average & & $\mathbf{2 5 8}$ & $\mathbf{1 2 4}$ \\
\hline
\end{tabular}

If, as I suspect, the use of ratio modifiers with negative adjectives is indeed problematic, then the proportion of ratio comparisons out of the total number of equative comparisons (i.e., the likelihood of modification by twice given the use of an equative) should be greater among positive adjectives than among their negative antonyms $(\mathrm{A} / \mathrm{B}>\mathrm{C} / \mathrm{D}){ }^{24}$

All in all, the licensing and frequency of use of ratio modifiers seems to be affected by a combination of several factors, one of which is the polarity of the adjective. The results confirm my expectation for about $75 \%$ of the adjectives.

\footnotetext{
${ }^{24}$ In order to test reliability, I searched for ratio comparisons with these 27 antonym pairs on a different day. The results were highly similar. There is a correlation of 0.99 between the two searches with regard to the proportion of ratio comparisons with a positive adjective out of the total number of ratio comparisons with that adjective and its negative antonym $(\mathrm{A} /(\mathrm{A}+\mathrm{C}))$. The high correlation persisted when I controlled for the adjectives' frequency by dividing the counts of ratio comparisons in the second search by counts of entries of the form $A D J$ for each adjective. I found a correlation of 0.95 between the rightmost row $(\mathrm{A} / \mathrm{B}) /(\mathrm{A} / \mathrm{B}+\mathrm{C} / \mathrm{D})$ in Table 3 and the corresponding row of the second search, where $\mathrm{B}$ and $\mathrm{D}$ represent the frequency of the adjective $A D J$.
} 
As presented in Block I of the table, in 78\% (21) of the antonym pairs, the proportion of ratio comparisons (out of the total number of equative comparisons) among the positive adjectives $(\mathrm{A} / \mathrm{B})$ is larger than the proportion of ratio comparisons (out of the total number of equative comparisons) among their negative antonyms (C/D). In three of these pairs, the difference is rather marginal (happy/ unhappy, ${ }^{25}$ warm/cold, and hot/cold), but given the large number of entries (and the significant effect on the other 18 pairs), this study supports the hypothesis that twice combines more often with positive than with negative adjectives.

Yet, as presented in Block II of the table, in $22 \%$ (6) of the antonym pairs, the pattern is reversed. The following sections explore these unexpected data. Section 5.3 addresses positive adjectives that resemble negative ones with respect to the (non-)licensing of measure phrases (e.g., warm) and/or ratio statements (e.g., the positive adjectives in Block II of Table 3). Section 5.4 addresses exceptional uses of negative adjectives with ratio modifiers and sometimes also measure phrases.

\subsection{Positive adjectives that resemble negative ones}

The present analysis directly captures properties of exceptional positive adjectives, like warm. The latter resemble their negative antonyms in that they only license numerical degree modifiers in the comparative (cf. \#twenty degrees warm versus twenty degrees warmer). The degrees of positive adjectives are not reversed, but they may well be transformed. This explains the infelicity of two degrees warm (as opposed to the felicity of two degrees warmer). It also captures our unclear intuitions concerning the zero point of warm, when interpreted as mapping objects to their temperature (as measured by a thermometer).

Why is it that the zero of this interpretation of warm is transformed? Entities that scientists claim possess no heat are mapped to zero on the Kelvin scale. However, they are not mapped to zero Celsius! The Celsius scale is transformed relative to the Kelvin scale. ${ }^{26}$ The existence of a transformed unit name like Celsius supports the view that temperature predicates may be associated with transformed temperature measures. In particular, entities with no heat are mapped to $-273^{\circ} \mathrm{C}$. We do not often encounter or discuss such entities, and we normally perceive entities to be without heat long before they reach $-273^{\circ}$. I submit that positive adjectives, when linked to external measures whose corresponding perceptual measures have a different zero point, are likely to be associated with a non-zero transformation value, i.e. with non-additive degree functions. Thus, we expect them (i) not to license ratio modifiers (or to do so relatively rarely, by allowing for secondary, context-depen-

\footnotetext{
25 Speakers often assert, for instance, that they are twice as happy, but merely as a manner of speech-a figurative way of stating that they are much happier. However, this obviously does not show that twice as happy is ungrammatical; in fact, it is completely grammatical! Note that even if quantities of happiness, sadness, love, etc. are mapped to numbers, the creation of a convention regarding unit objects is hardly possible because these quantities are inner states which are never accessible to the whole community. Thus, no numerical degree modifiers exist for these measures (Sassoon 2010; see also the discussion in Sect. 5.3 below).

${ }^{26}$ Entities with the heat of $\mathrm{r}$ Kelvin units are mapped to $\mathrm{r}-273^{\circ} \mathrm{C}$ (for further discussion of related linguistic facts and their account see Sassoon, 2007, 2010).
} 
dent, additive interpretations), although (ii) since they derive from some additive measuring system by transformation, these measures are likely to have unit names and to license numerical degree modifiers in the comparative.

The zero in non-additive conventional scales like the Celsius scale is assigned to some salient, highly relevant point (e.g., the freezing point of water). But this is an arbitrary choice. The zero could have been assigned to many other points, equally easy to recognize and at least as relevant to discourses about, in this case, temperature. In parallel, this paper claims that, generally, the functions of negative adjectives are transformed so as to locate the zero among entities that might be under discussion in their contexts of use.

Importantly, I do not (and cannot) claim that the average language-acquiring child has access to scientific knowledge regarding, e.g., Kelvin and Celsius thermometers. If anything it is the other way around, insofar as scientific concepts are often rooted in primary perception. Speakers tend to agree that locating the exact point where something ceases to contain heat is not an easy matter. That suffices for me to say that the zero point in the predominant interpretation of temperature predicates is undetermined. Also, scientists invent and use transformed thermometers because, like all of us, they too find the point at which entities cease to have any heat/temperature hardly ever relevant to them in daily-life conversations about temperatures. Then again, the semantic component of grammar constantly evolves and scientific concepts penetrate into it. Evidence for that is the fact that sometimes we do interpret temperature predicates as non-transformed (surely, scientists do). That must be the case when we accept non-figurative twice statements, i.e. when we accept "A is twice as hot as B" as meaning that "the quantity of heat in A is two times the quantity of heat in B'. Still, in non-scientific contexts, the transformed interpretation seems to be the more salient.

Other examples include adjectives like heavy or rich. Richness is often measured by the amount of money one's possessions are worth. Still, zero richness is not conventionally or intuitively identified with entities having absolutely no possession. Similarly, a lack of a feeling of 'heaviness' can occur in things with more than zero weight. The air or feathers are not heavy at all, though they do have some weight. Languages may vary as to whether the degree functions of adjectives like, e.g., rich, heavy, or warm (as measuring amounts of possession, weight, or external temperature, respectively) are transformed (are affected by, e.g., our perception of such stimuli) or not. Thus, languages may differ as to the licensing of ratio modifiers, as well as of numerical degree modifiers in non-comparative forms. $^{27}$

Certain readers may still ask why this is so. If adjectival semantics is governed by our world knowledge and intuitions concerning the measures that adjectives are associated with, one would expect a strong correlation between an adjective's meaning and the presence or absence of transformation. One would expect that

\footnotetext{
${ }^{27}$ Further examples in point may be the two Hebrew nominalizations miskal 'weight' and koved 'heaviness'. Only the former licenses measure phrases (mishkall \#koved shney kilos; 'weight/ \#heaviness of two kilos') and ratio phrases (mishkall ?koved kaful; 'double weight/ ?heaviness'). The existence of several nominalizations with different properties independently supports the view that the corresponding adjective carries both transformed and non-transformed interpretations.
} 
with my theory we will be able to formally predict when a predicate is to be interpreted as transformed. At this point I should remind readers that this is never the case with grammaticized semantic distinctions. When intuitive semantic distinctions are incorporated into grammar, they turn into formal features that can be associated with words quite arbitrarily. An example in point is the female-male gender distinction, as well as the mass-count distinction. Though e.g. the word for water is likely to classify as a mass noun in every language, for many other words we cannot predict whether they will be classified as mass or count in a given language. Words like furniture are count in Italian, mass in English, and both in Hebrew. For relevant discussion see Chierchia (1998), who describes words like furniture as 'fake mass nouns', i.e., grammatically mass (they do not combine with numerals, *three furnitures) but cognitively count (experimental evidence shows that furniture patterns with count nouns when it comes to counting and individuating tasks). In the same way, adjectives related to measures regarding whose zero point we have no conventions, intuitions, or important experiences are likely to be classified as transformed. The classification of other adjectives is not predictable. This shouldn't be surprising or troubling: since the standard type of gradable adjectives varies across and within languages, why wouldn't the transformation value do so as well?

Moreover, for any additive adjectival interpretation, we can in principle construct an adjectival interpretation that is exactly similar except transformed. Thus, we can expect languages to contain near-synonyms that differ with respect to transformation. For example, according to Schwarzschild (2005), tall in French ('grande') cannot license measure phrases. I'd say that it has a transformed interpretation. Children, of course, can learn this semantic distinction based not on semantic features alone, but also on the way such adjectives are used, e.g., with/without measure phrases, in just the same way as they can learn about mass/ count words based on whether they are used with numerals or not. In fact, by Google-searching for potential examples of near-synonyms, I have found that happy seems to have additive uses, while glad does not (based on their estimated counts of twicecomparisons, which were 2,880 and 2, respectively; for conversion into fractions of total occurrences, see Table 3); smart has additive uses (15,500 counts), while wise does not (235 counts); and fast has additive uses (1,444,000 counts), while quick does not (798 counts). In fact, the reversed pattern found for quick-slow (798 vs. 31,700 counts, respectively) may also result from slow being the reverse of fast, not of quick, in most of these uses (but see also the discussion of deviation-froma-midpoint interpretations below). ${ }^{28}$

Most importantly, the distributional findings in Table 3 provide supporting evidence for the analysis of many positive adjectives as transformed, despite not being reversed.

\footnotetext{
${ }^{28}$ It may well be that aside from differences in connotation (rendering e.g. smartness relatively more measurable than wisdom), speech register plays a role in differentiating among near-synonyms here (C. Bartels, p.c.). Figurative twice-comparisons are colloquial, informal constructions, and thus more likely to employ the more common, colloquial choice of adjective: smart rather than wise, fast rather than quick, happy rather than glad.
} 
First, the fact that both the positive and the negative members of 23 of the 50 antonym pairs for which I Google-searched have less than 1,000 counts of ratio comparisons with twice (Block III of Table 3) is consistent with the idea that the positive counterparts of transformed negative adjectives may also be transformed.

Second, Block II of Table 3 presents a small group of adjective pairs that appear to pattern differently than expected. The negative adjectives here occur more often with ratio modifiers than their positive antonyms. Are they reversed and nontransformed? There is good reason to think that this is not the case. Rather, in these pairs the positive adjectives as well are transformed.

Had the negative adjectives in Block II been non-transformed, we would have expected twice to modify their equatives as often as it modifies the equatives of the non-transformed positive adjectives in Block I. However, twice is significantly rarer with the negative adjectives of Block II than with the positive adjectives of Block I ( 2.03 vs. $4.03 \%$, on average). Moreover, twice is even rarer in the positive adjectives in Block II (0.54\%, on average). This would have been unexpected if these were interpreted as non-transformed.

To illustrate this point, let us divide the adjectives into those that tend to combine with twice more than once per 100 equatives, versus those that do not (i.e., do so less than once per 100 equatives). Importantly, only two negative adjectives tend to combine with twice more than once per 100 equatives (slow and bad), while all the rest (90\% of the 27 negative adjectives in Blocks I and II), as well as many positive adjectives, do not.

Figure 1 illustrates this in a graph. Significantly, the values of the negative adjectives are clearly located between the levels 0 and $1 \%$ (i.e., less than 1 use of twice per 100 equatives), with but two exceptions, bad and slow (the latter is represented twice; once in comparison with fast and once in comparison with quick). Thus, the difference between Block I and II of Table 3 concerns mainly the values of positive adjectives. In Block II, but not in Block I, these values approximate $0 \%$.

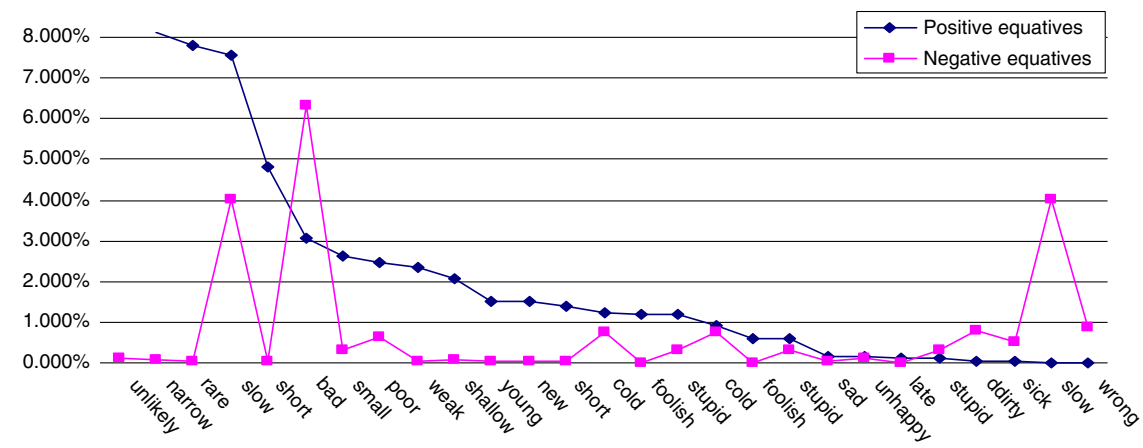

Fig. 1 Distribution of twice in equatives with positive versus negative antonyms

The unexpected distribution of twice among the antonyms in Block II is, therefore, due to the non-use of twice with certain positive adjectives, which is consistent with them being predominantly transformed, like their negative ant- 
onyms. The next section makes sense of the remaining two exceptions, bad and slow (which appear to pattern with (50d), i.e. to be interpreted as predominantly reversed but not transformed).

At any rate, we must also keep in mind that additional factors may play a role in explaining the non-use of twice. In particular, a viable possibility is that some positive adjectives tend to associate with base functions which are not additive. Consider, for instance, the adjective felicitous. We often have intuitions about felicity contrasts between sentences, but never about absolute levels of felicity. Thus, felicitous resembles, e.g., heavy, whose degree function transforms the values of an additive base function. It is difference-preserving, but not ratio-preserving. Its association with a transformation value has no effect, given that it maps to zero an arbitrarily chosen, context-variant amount of felicity in the first place (Featherston, to appear; Sassoon 2010). Likewise, the data this paper addresses follows just as much from the assumption that the base functions of weight and temperature adjectives or of psychological adjectives like happy are difference-preserving but not additive (except in scientific contexts).

Last but not least, the present proposal may have consequences with regard to evaluativity. Rett (2007) argues that negative adjectives tend more towards evaluative implications (e.g., the question How tall is the ostrich? and the equative The ostrich is as tall as the chicken do not imply that the ostrich is tall, while the question How short is the ostrich? and the equative The ostrich is as short as the chicken do imply that the ostrich is short). However, as Krasikova (2008) observes, gradable predicates in Russian that are not morphologically marked for comparison trigger evaluative implications regardless of their polarity. Interestingly, they also do not combine with measure phrases! While Krasikova (2008) proposes that different constraints govern the distribution of measure phrases and evaluative interpretations in English and Russian, the present analysis suggests that an account for the two languages in terms of one principle may be possible (by connecting evaluativity and transformation). ${ }^{29}$

In conclusion, the proposal that a transformation procedure systematically affects adjectival interpretations explains also why some positive adjectives license numerical degree modifiers only in the comparative, and it correctly predicts that this would be the case when our intuition is that the zero point is uncertain and/or irrelevant. Future research should inquire whether evaluativity, which seems to

\footnotetext{
29 The relevant generalization is that adjectives that do not license measure phrases in the non-comparative form are evaluative. (I am indebted to Micha Breakstone for drawing my attention to this generalization; for related discussion see Bierwisch 1989; Breakstone 2009.) This generalization seems to apply to all the negative adjectives in English and Russian, and to all the positive ones in Russian, but, crucially, also to those positive adjectives in English that fail to license measure phrases. Examples in point are heavy, fat, rich, and warm (cf. the infelicity of \#twenty degrees warm, \#two million euros rich, and \#thirty kilograms heavy/fat and the evaluativity and hence odd nature of, for instance, ?This feather is as heavy as that one and ?This ice cream is as warm as that one). Rett's (2007) theory, according to which evaluativity pertains to 'marked' (i.e., negative) adjectives, fails to capture these facts. However, they directly follow if evaluativity is seen as characterizing adjectives whose predominant interpretation is transformed by an unspecified value. Note that to accommodate the facts, Rett's (2007) analysis has to be heavily modified, as it derives evaluativity from a comparison with an alternative unmarked (positive) antonym, whereas in the case of positive evaluative adjectives the antonym (being negative and evaluative) is not unmarked.
} 
characterize adjectives with transformed interpretations, can be derived from the existence of a transformation value.

\subsection{Negative adjectives that resemble positive ones}

The comprehensive theory of negative antonymy ties together function reversal and transformation. By default, negative adjectives are transformed by an unspecified value. This proposal correctly predicts the fact that statements with, e.g., twice as short as are less acceptable and less often used than statements with twice as tall as. But what happens when we do use them?

It is well known that the interpretation of adjectives is remarkably amenable to contextual modification (adaptation to ad-hoc contextual purposes; cf. Kennedy and McNally 2005). Context may affect all the default features of adjectival degree functions. For example, Kennedy and McNally (2005) have observed that adjectives like $d r y$ have a default absolute-standard interpretation; thus we understand statements like The floor is dry to convey that the floor is completely dry - there is no humidity at all on the surface of the floor. But in certain uses, dry is interpreted as a relative-standard adjective; for example, we understand statements like My skin is dry to convey that the humidity of my skin is below some standard.

The status of the transformation value (whether it is necessarily thought to equal zero or not) may change in a similar fashion. For example, consider a situation in which the length of different short stories is measured based on the number of words in each story. In this situation, some speakers may utter and accept as felicitous ratio statements like This story is twice as short as that one. In the given situation, short's degree function is indeed locally based on an ad hoc 'scientific' measuring convention (number of words); that is, the degree function of short in this ad hoc use is reversed but not transformed. Indeed, the association of adjectives with ad hoc additive measures is most typical of contexts of scientific or technological inquiry. For example, many search results for twice as slow as regard measurements of speed of software, discs, processors, etc.; the same is true of positive adjectives, e.g. uses of twice as heavy often regard stars or chemical particles.

The negative adjective short has several other types of secondary interpretations. In statements like I am short of money, the degree function of short can be described as measuring the lack of some 'stuff' other than height. The same holds true when short is used to describe temporal length, length of musical notes, etc. Here, short does not function as the negative antonym of tall. We need a separate examination to determine whether the degree functions of short in these uses are transformed or not. At any rate, it is definitely the case that 'additive', convention-based interpretations (such as the word-count measure for short stories) do not form the dominant or default interpretation of short, as indicated by the fact that the likelihood of modification by twice is drastically smaller for the negative equative as short as than for each of its positive counterparts.

Significantly (and also surprisingly), some of the exceptional uses of negative adjectives can actually be explained by their association with a transformation value. Let me explain this important point in some detail. 
As observed by Kennedy (1999, 2001), negative adjectives (as well as positive ones) typically have a secondary interpretation whereby they measure deviations from a midpoint. Speakers who accept cross-polar comparisons (such as Dan is taller than Mary is short or Your clock is faster than mine is slow) typically interpret the adjectives in this way (e.g., the distance from some standard height or some required time point is measured by both the positive and the negative antonyms).

First, note that the general availability of a deviation-from-a-midpoint interpretation for positive and negative adjectives provides additional motivation for the definitions in (14). In these interpretations, the transformation value is contextually restricted to be the value of some agreed-upon entity. Consider, for example, a deviation-from-the-required-time interpretation for early and late in a context $\mathrm{c}$ in which the required time is the time of some event $\mathrm{x}_{\mathrm{e}}$ (say, a certain meeting). Intuitively, early and late share an additive base function in each $\mathrm{t}$ in $\mathrm{T}_{\mathrm{c}}$, representing the time of different events in $\mathrm{t}$ (arrivals to the meeting; cf. (52a)). The transformation value is the meeting time in $\mathrm{t}(52 \mathrm{~b})$. According to the definitions of antonymy and polarity in $(14 \mathrm{a}-\mathrm{c})$, then, in every $\mathrm{t}$ in $\mathrm{T}_{\mathrm{c}}$, these adjectives measure deviations of arrival times from the meeting time, as illustrated in $(52 \mathrm{c}, \mathrm{d})$ :

$$
\begin{aligned}
& \text { a. } f(\text { early }, \mathrm{t})=f(\text { late }, \mathrm{t})=\lambda \mathrm{x} \in \mathrm{D}_{\mathrm{x}} . \operatorname{Time}_{\mathrm{t}}(\mathrm{x}) . \\
& \text { b. } \operatorname{Tran}(\text { early }, \mathrm{t})=\operatorname{Tran}(\text { late }, \mathrm{t})=\operatorname{Time}_{\mathrm{t}}\left(\mathrm{x}_{\mathrm{e}}\right) . \\
& \text { c. } \mathbf{f}_{\text {late }, \mathrm{t}}=\lambda \mathrm{y} \in \mathrm{D}_{\mathrm{x}} \cdot f(\text { late }, \mathrm{t})(\mathrm{y})-\operatorname{Tran}_{(\text {late }, \mathrm{t})} \\
&=\lambda \mathrm{y} \in \mathrm{D}_{\mathrm{x}} \cdot \operatorname{Time}_{\mathrm{t}}(\mathrm{y})-\operatorname{Time}_{\mathrm{t}}\left(\mathrm{x}_{\mathrm{e}}\right) \\
& \text { d. } \quad \mathbf{f}_{\text {early }, \mathrm{t}}=\lambda \mathrm{y} \in \mathrm{D}_{\mathrm{x}} \cdot \operatorname{Tran}_{(\text {early }, \mathrm{t})-f(\text { early }, \mathrm{t})(\mathrm{y})} \\
&=\lambda \mathrm{y} \in \mathrm{D}_{\mathrm{x}} . \operatorname{Time}_{\mathrm{t}}\left(\mathrm{x}_{\mathrm{e}}\right)-\operatorname{Time}_{\mathrm{t}}(\mathrm{y}) .
\end{aligned}
$$

For example, if the meeting time is $10 \mathrm{r}_{\mathrm{h}, \mathrm{t}}$ in $\mathrm{t}$, arrival at the required time is neither late nor early. It has a zero deviation from itself $\left(\mathrm{f}_{\mathrm{late}, \mathrm{t}}\left(\mathrm{x}_{\mathrm{e}}\right)=10 \mathrm{r}_{\mathrm{h}, \mathrm{t}}-10 \mathrm{r}_{\mathrm{h}, \mathrm{t}}=0\right)$. But if the time Sam arrived is $11 \mathrm{r}_{\mathrm{h}}\left(\mathrm{r}_{\mathrm{h}, \mathrm{t}}\right.$ being the time value of an hour in $\mathrm{t}$ ), Sam is one hour late $\left(\mathrm{f}_{\text {late, } \mathrm{t}}\left(\llbracket \operatorname{Sam} \rrbracket_{\mathrm{t}}\right)=11 \mathrm{r}_{\mathrm{h}, \mathrm{t}}-10 \mathrm{r}_{\mathrm{h}, \mathrm{t}}=1 \mathrm{r}_{\mathrm{h}, \mathrm{t}}\right)$. Similarly, if the time of Dan's arrival is $8 \mathrm{r}_{\mathrm{h}, \mathrm{t}}$, then Dan is two hours early $\left(\mathrm{f}_{\text {early }, \mathrm{t}}(\llbracket \mathrm{Dan} \rrbracket \mathrm{t})=10 \mathrm{r}_{\mathrm{h}, \mathrm{t}}-8 \mathrm{r}_{\mathrm{h}, \mathrm{t}}=2 \mathrm{r}_{\mathrm{h}, \mathrm{t}}\right)$. We can describe this situation as one in which Dan arrived earlier than Sam arrived late. Thus, functions of precisely the forms given by definitions $(14 \mathrm{a}-\mathrm{c})$ (with the transformation value in every $\mathrm{t}$ in $\mathrm{T}_{\mathrm{c}}$ specified to be the value $f($ late, $\mathrm{t}$ ) assigns to an agreed-upon entity $\mathrm{x}_{\mathrm{e}}$ ) give us the results we want.

Importantly, interpretations like those in $(52 \mathrm{c}, \mathrm{d})$ are inherently comparative - they are always based on a calculation of the difference between the degrees of two agreed-upon entities. This means that the transformation values of the base function, if there are any, cancel out. The resulting functions are therefore additive with respect to 'deviation from the required time'. In this interpretation, then, slow and early are positive ('non-reversed') with respect to measures of deviations. Bigger deviations have bigger values, and zero is assigned precisely to arrival events not deviating at all from the required time. Hence, unsurprisingly, in these interpretations the antonyms easily compare, and they even license measure phrases, e.g., Dan may be two minutes latel early, and his clock may be 2 minutes 
slow/ fast (meaning that the difference between the time according to Dan's clock and the 'actual' time, say, 10:30 Greenwich time, is $2 \mathrm{~min}$ ). ${ }^{30}$ The fact that slow and early license measure phrases is consistent with the fact that this interpretation has the basic default ('dominant') form of a reversed and transformed function. Perhaps it is even more dominant than the one whereby the transformation value is unrestricted (as in Dan woke up late; he always arrives late, etc.)

Consider the sentence 2 o'clock is twice as late as 1 . We can only make sense of it by interpreting late as measuring deviations from some event planned to occur at 12 o'clock. Likewise with twice as early as. So twice combines with late and early only when the transformation value is specified (corresponds to the time of an agreed-upon entity), i.e. in a difference (deviation-from-a-midpoint) interpretation. Presumably, examples of deviation measures can also be construed for good and bad in their different senses, e.g., as measures of students' grades in mathematics, of amounts and weights of good and evil deeds, etc.

Finally, arriving an hour early, Dan is "minus one hour late", so to speak, but in an attempt to avoid negative degrees for entities under discussion-the basic motivation of transformation values in the first place (cf. Sect. 3.2) -we tend to grade with late only arrivals that are late (in comparison with the transformation value), and to grade with early only arrivals that are early. The ban on negative degrees for entities under discussion, then, justifies the very fact that we use negative adjectives in degree constructions at all (i.e., that we bother ranking entities with reversed and transformed measures). ${ }^{31}$

To wrap up: if we restrict the transformation value in the way just described, the functions denoted by negative adjectives turn from being 'transformed by an unspecified value' into being difference measures, like those their derived comparatives denote. With this observation we can now consider (as a last point) different, yet similar cases.

Unhappy and sad can be interpreted either as negative antonyms of adjectives like happy and glad or as (linguistically) positive adjectives, in the sense of being directly linked to a measure of (amounts, so to speak, of) sorrow or unhappiness. Nonetheless, crucially, perceptual measures of happiness and unhappiness (or joy and sorrow) are usually felt to be linearly reversed relative to each other (e.g., Dan is happier than Sam in some respect to some extent iff Sam is unhappier than Dan in that respect to that extent). For this reason, happy and unhappy and glad and sad

\footnotetext{
${ }^{30}$ Here is another example, for interested readers, with a deviation-from-a-midpoint interpretation for slow and fast. Intuitively, the base function they share represents the time shown by different clocks $\mathrm{x}$, $f($ fast, $\mathrm{t})=f($ slow, $\mathrm{t})=\lambda \mathrm{x} \in \mathrm{D}_{\mathrm{x}}$. Time $\mathrm{t}(\mathrm{x})$. The transformation value in each $\mathrm{t}$ is the actual time (say, the time a precise clock $x_{p}$ shows in $\left.t\right), \operatorname{Tran}(f a s t, t)=\operatorname{Tran}($ slow, $t)=\operatorname{Time}_{t}\left(x_{p}\right)$, meaning that these adjectives measure deviations of clocks from the actual time in every $t$ in $T_{c}: \mathbf{f}_{\mathbf{f a s t}, t}=\lambda \mathrm{y} \in \mathrm{D}_{\mathrm{x}} \cdot \operatorname{Time}_{\mathrm{t}}(\mathrm{y})-\operatorname{Time}_{\mathrm{t}}\left(\mathrm{x}_{\mathrm{p}}\right)$ and $\mathbf{f}_{\text {slow,t }}=\lambda \mathrm{y} \in \mathrm{D}_{\mathrm{x}} \cdot$ Time $_{\mathrm{t}}\left(\mathrm{x}_{\mathrm{p}}\right)-$ Time $_{\mathrm{t}}(\mathrm{y})$. Thus, if the time value of $\mathrm{x}_{\mathrm{p}}$ is $10 \mathrm{r}_{\mathrm{h}, \mathrm{t}}$ in $\mathrm{t}$, the precise clock is neither slow nor fast (it has a zero deviation from itself: $\mathrm{f}_{\text {slow }, \mathrm{t}}\left(\mathrm{x}_{\mathrm{p}}\right)=10 \mathrm{r}_{\mathrm{h}, \mathrm{t}}-10 \mathrm{r}_{\mathrm{h}, \mathrm{t}}=0$ ). However, if the time my clock shows is $9 \mathrm{r}_{\mathrm{h}, \mathrm{t}}\left(\mathrm{r}_{\mathrm{h}, \mathrm{t}}\right.$ being the value of $1 \mathrm{~h}$ in $\left.\mathrm{t}\right)$, then my clock is one hour slow $\left(\mathrm{f}_{\text {slow,t }}(\llbracket \mathrm{my}\right.$ clock $\left.\rrbracket_{\mathrm{t}}\right)=10 \mathrm{r}_{\mathrm{h}, \mathrm{t}}-9 \mathrm{r}_{\mathrm{h}, \mathrm{t}}=1 \mathrm{r}_{\mathrm{h}, \mathrm{t}}$ ), and if the time your clock shows is $11 \mathrm{r}_{\mathrm{h}}$, your clock is one hour fast $\left(\mathrm{f}_{\text {fast }, \mathrm{t}}\left(\llbracket\right.\right.$ your clock $\left.\left.\rrbracket_{\mathrm{t}}\right)=11 \mathrm{r}_{\mathrm{h}, \mathrm{t}}-10 \mathrm{r}_{\mathrm{h}, \mathrm{t}}=1 \mathrm{r}_{\mathrm{h}, \mathrm{t}}\right)$.

31 Notice that it disappears in the comparative. Thus we can report that Dan arrived earlier than Sam when both are late. In such uni-polar comparisons, specifying transformation values makes no sense: they cancel out anyways.
} 
satisfy the criterion for antonymy. They can be construed as sharing a base function, compared to which unhappy/sad are linearly reversed, and are therefore considered antonyms according to the definitions in $(14 a-c)$.

Importantly, when both antonyms of a given pair can easily be described as transformed (both tend to license neither twice nor measure phrases), it makes it harder to determine which one is the negative. The good news is that the proposal to define negative antonyms as reversed and transformed, and positive ones as nonreversed and either transformed or not, has the advantage that it entails that in some cases (i.e., when the positive is transformed) there will be symmetry between the two antonyms, which will make it difficult to say which one is the negative (which one is based on reversal of the function of the other).

Examples in point are found in Block II of Table 3, such as, for instance, the antonym pair healthy-sick, where $\sim 0.02 \%$ of equatives with healthy are twice as-equatives, and $\sim 0.5 \%$ of equatives with sick are twice as-equatives-all in all very few ratio statements altogether (1,420 results for twice as sick as versus 193 for twice as healthy as). Note that sick has secondary interpretations, which the antonym healthy does not seem to share (as, for example, in I am sick of not getting a job). In addition, as is the case with short, ad hoc measures may be associated with sick and form secondary interpretations that trigger uses of twice as sick which are not even reversed. Consider, for example, the statement Dan is three aspirins sick versus the infelicitous statement \#Dan is three aspirins healthy (I thank Louise McNally for drawing my attention to this example). Here, sick is associated with a non-transformed, and in fact non-reversed, additive measure function (the more aspirins you need, the sicker you are). This measure phrase is, nonetheless, novel, and its use is still amusingly anecdotal, showing that this interpretation has hardly (as yet) become a default one for sick (no unit name exists whose dimension set, as specified in the mental lexicon, includes sick). For this reason, together with the fact that sick does not often associate with twice, sick should not normally be regarded as the positive element in this antonym pair. Finally, note that for doctors, adjectives like healthy/sick with respect to blood pressure measure deviations from some ideal blood pressure value(s). In this interpretation sick is positive-the larger the deviation, the larger the value it assigns (for a discussion of such distance adjectives see Sassoon 2007).

Another example is the antonym pair clean-dirty. I classify dirty as the positive member of this antonym pair, because the (default) interpretation of these two adjectives seems to be related to measures of quantities of dirt. Thus, it is unsurprising that dirty patterns with positive adjectives and clean with negative (reversed and transformed) ones. The negative flavor of dirty may result from a culturally biased negative attitude towards dirt (same with old and our culturally biased attitudes to age). This classification is supported by the fact that it is hard to identify a zero point for clean, perhaps because dirty has no maximal point (there is no 'dirtiest' point). This is the general tendency in antonym pairs (seen in Block I of Table 3). Positive adjectives tend not to have a maximal point (e.g., there is no tallest point), a fact which renders the zero point of their negative antonym undefined. Moreover, newly invented measure phrases such as two stains or twenty grains of dust seem to be more compatible with dirty than with clean (though they 
are quite odd with both; e.g., compare *two stains clean to ?twenty stains dirty). Similar doubts arise also concerning adjectives like bad and wrong. ${ }^{32,33}$

To summarize, the present analysis distinguishes between function reversal and linear transformation (zero displacement), while explaining why there is, nonetheless, a tight correlation between the two. The analysis of negative adjectives as reversed, and therefore, by default, transformed, is interesting and non-trivial because it encapsulates the characteristics of most of the uses of negative adjectives. Reversal fails to trigger the displacement of the zero only in a small minority of cases, and these are barely ever default interpretations of negative adjectives. In some cases, zero displacement creates difference measures, which are additive with respect to differences. These are the deviation-from-a-midpoint interpretations. They can become very dominant (as they bear the default interpretation of negative adjectives), to the point of allowing the licensing of measure phrases.

\subsection{A short comparison with previous theories}

As mentioned in footnote 4 above, the present proposal bears resemblance to interval ('extent') theories of antonymy (e.g., von Stechow 1984a, b; Kennedy 1999, 2001). Yet it improves upon them in terms of empirical coverage.

First, warm is a positive adjective, but does not allow for numerical degree modification except in the comparative. The 'extent' analysis of antonymy fails to capture this fact. In this analysis, degrees of positive adjectives, including warm, are initial intervals and degrees of negative adjectives are final intervals, so it is incorrectly predicted that only the latter do not combine with numerical degree modifiers. The present proposal does capture these facts by allowing transformation without reversal. While negative adjectives are reversed and transformed, positive adjectives are not reversed, but may well be transformed and hence may not license measure phrases.

Second, these theories analyze Dan is two meters short as equivalent to Dan is as short as two meters. However, while the former is utterly ungrammatical and polarity dependent, the latter is less unacceptable and its odd nature is not due to polarity, given that \#Dan is as tall as two meters is equally odd. Furthermore, the corresponding comparative, Dan is shorter than two meters, is perfectly acceptable and natural, a fact that is not straightforwardly captured (Landman 2005). By

\footnotetext{
32 Adjectives like dirty may turn out to be predominantly negative, based on diagnostic tests beyond those I consider in this paper. Rullmann (1995) and Heim (2006b, 2008) discuss and address scopal differences between positive and negative adjectives. Validation of these scope facts across antonym pairs and languages, as well as a complete account, await further research. This issue falls outside the limits of this paper, as does the question of whether there are discrepancies between the results of Rullmann's and Heim's tests and of the tests reviewed above.

33 Israel (2004) notes that while some positive adjectives combine with the negative prefix un-, negative adjectives never do (cf. unhappy versus \#unsad; unsafe versus \#undangerous; unwise versus \#unfoolish, etc.). Notice, however, that none of the positive adjectives in the paradigmatic antonym pairs mentioned in Sect. 1 combines with un- (\#untall, \#unwide, \#undeep, \#unold, etc.) Thus the measure-phrase test and the negative-prefix test seem to apply to non-overlapping sets of antonym pairs; the actual restrictions on the licensing of $u n$ - fall beyond the scope of this paper.
} 
contrast, the analysis I propose in this paper does capture this data in a rather natural (or at least standard) way (cf. Sect. 4.3.2).

The present proposal also deviates slightly from alternative theories of measure phrase licensing.

First, there are the accounts of Schwarzschild (2005) and Landman (2005). Both of these have to inherently rely on type ambiguity in adjectives that license measure phrases. They do so by virtue of an additional special interpretation (the 'interval' interpretation in Schwarzschild 2005 and the 'dimensional' interpretation in Landman 2005). On the present proposal, by contrast, the facts follow directly from the basic interpretation of adjectives (a predominantly non-transformed interpretation).

Second, Winter (2005) attempts to explain facts concerning measure phrase licensing in positive adjectives based, roughly, on the adjective's scale being unbound from above; for example, maximum tallness does not exist, but maximum shortness (= zero tallness), in principle, does. I find Winter's (2005) proposal problematic for the following reasons. The scale of open and close is bound when applied to standard doors, but measure phrases are licensed, as in 60 degrees open and $60 \%$ open. ${ }^{34}$ Conversely, warm, hot, and cold are unbound, yet do not license measure phrases. To explain the latter, Winter (2005) argues that measure phrases do not combine with adjectives that do not exhaust their scale, like warm, which cannot refer to entities with zero temperature. But for this to work for, e.g., heavy, entities perceived as having zero weight must exist. This is more dubious. (Perhaps the air?) Besides, tall and wide do license measure phrases, although they do not exhaust their scale. Languages do treat surfaces and points as (abstract) entities; if so, entities with, e.g., zero height exist.

\section{Conclusions}

- The basic motivation for transformation values is that they correctly capture our uncertainty concerning the zero points of negative adjectives.

- Moreover, they provide a straightforward account of significant contrasts between positive and negative adjectives in paradigmatic antonym pairs.

- In addition, they provide a straightforward account of similarities between nonparadigmatic positive adjectives and their negative antonyms.

\footnotetext{
34 Winter's proposal correctly predicts that empty and full do not license measure phrases (for Winter that is because they are both bound). However, notice that, as Winter himself mentions, these adjectives are somewhat odd with measure phrases even in the comparative (as illustrated by the oddness of ??This bucket is two liters fuller/emptier than that one), which suggests that some additional independent factor is at play here (see relevant discussion of the interpretation of full in Sassoon 2007, Chaps. 5 and 7). Furthermore, intuitively, a glass can count as full while not being completely full (the interpretations of full and completely full are not quite identical). There is some context dependency regarding the standard (or maximum point) of full, then, which produces vagueness with regard to the zero point of empty. This, together with the fact that these adjectives are almost never used with twice (Google searching, I have found less than an estimated 1,000 uses for both antonyms together), supports the view that they are represented as transformed.
} 
- Are there any negative adjectives that are "reversed but not transformed"? The answer given in this paper is 'No'. Adjectives that appear exceptional have been explained as having positive counterparts that have been transformed, leaving doubts concerning only very few cases, if any (e.g., bad and slow). However, future research should study the data more thoroughly within and across languages. Such research might show that many negative adjectives do tend to regularly license ratio modifiers and measure phrases. If so, that would be better captured by the narrow rule of antonymy, namely by assuming that negative adjectives are linearly reversed, and that adjectives associated with additive measures (like tall, short, heavy, light, etc.) license measure phrases iff they are not transformed.

- Finally, future research should establish how well the present proposal combines with accounts of cross-polar nomalies and sub-deletion comparisons in general (cf. Sect. 4.4), and whether transformation values can explain evaluative implications (as these characterize adjectives that fail to license measure phrases, cf. Sect. 5.3). Moreover, positive and negative adjectives seem to differ also with regard to scope interactions and the licensing of negative polarity items (Kennedy 1999; Heim 2006b, 2008), topics not addressed here at all.

Open Access This article is distributed under the terms of the Creative Commons Attribution Noncommercial License which permits any noncommercial use, distribution, and reproduction in any medium, provided the original author(s) and source are credited.

\section{References}

Bale, Alan Clinton. 2008. A universal scale of comparison. Linguistics and Philosophy 31 (1): 1-55.

Bierwisch, Manfred. 1989. The semantics of gradation. In Dimensional adjectives: Grammatical structure and conceptual interpretation, ed. Manfred Bierwisch and Ewald Lang, 71-261. Berlin: Springer-Verlag.

Brasoveanu, Adrian. 2009. Measure noun polisemy and monotonicity: Evidence from Romanian pseudopartitives. In Proceedings of the 38th meeting of the North East linguistic Society, 139-150. Amherst, MA.: GLSA.

Breakstone, Micha. 2009. Inherently evaluative predicates. Manuscript, MIT.

Bresnan, Joan.1973. Syntax of the comparatives construction in English. Linguistic Inquiry 4: $275-345$.

Büring, Daniel. 2007. Cross-polar nomalies. In Proceedings of Semantics and Linguistic Theory 17. Ithaca, NY: CLC Publications.

Chierchia, Gennaro. 1998. Plurality of mass nouns and the notion of semantic parameter. In Events and Grammar, ed. Susan Rothstein, 53-103. Dordrecht: Kluwer.

Cresswell, Max. 1976. The Semantics of degree. In Montague Grammar, ed. Barbara H. Partee, 261-292. New York: Academic Press.

Featherston S. (to appear) Why linguistics needs boiling and freezing points. To appear In Fruits: The productive application of evidence to linguistic problems. Berlin: de Gruyter.

Fine, Kit. 1975. Vagueness, truth and logic. Synthese 54: 235-259. Reprinted in Vagueness: a reader, ed. Rosanna Keefe and Peter Smith, 119-150. Cambridge, MA: MIT Press, 1996.

Fox, Danny. 2007. Too many alternatives: density, symmetry and other predicaments. In Proceedings of SALT 16, ed. M. Gibson and T. Friedman. Ithaca, NY: CLC Publications.

Fox, Danny, and Martin Hackl. 2006. The universal density of measurement. Linguistics and Philosophy 29 (5): 537-586.

Giora, Rachel. 2006. Is negation unique? On the processes and products of phrasal negation. Journal of Pragmatics 38: 979-980. 
Gobbo, Camilla, and Franca Agnoli. 1985. Comprehension of two types of negative comparisons in children. Journal of Psycholinguistic Research 14 (3): 301-316.

Heim, Irene. 2000. Degree operators and scope. In Proceedings of SALT 10. Ithaca, NY: CLC Publications.

Heim Irene, 2001. Degree operators and scope. In Audiatur Vox apientiae. A Festschrift for Arnim von Stechow, ed. Caroline Féry and Wolfgang Sternefeld, 214-239. Berlin: Akademie-Verlag.

Heim, Irene. 2006a. Remarks on comparative clauses as generalized quantifiers. Manuscript, MIT.

Heim, Irene. 2006b. Little. In Proceedings of SALT 16, ed. M. Gibson and J. Howell, Cornell University, Ithaca: CLC Publications.

Heim, Irene. 2008. Decomposing Antonyms? Proceedings of Sinn und Bedeutung 12: 212-225. OSLO.

Heim, Irene, and Angelika Kratzer. 1998. Semantics in generative grammar. Malden: Blackwell.

Horn, Laurence R. 1972. On the semantic properties of logical operators in English. PhD diss., University of California, Los Angeles.

Horn, Laurence R. 1989. A natural history of negation. Chicago: The University of Chicago Press.

Israel, Michael. 2004.The pragmatics of polarity. In The handbook of pragmatics, ed. L. Horn and G. Ward, pp. 701-723. Malden: Blackwell.

Kamp, Hans. 1975. Two theories about adjectives. In Formal semantics for natural language, ed. Edward Keenan 123-155. Cambridge: Cambridge University Press.

Kennedy, Christopher. 1999. Projecting the adjective: The syntax and semantics of gradability and comparison. New York: Garland. (1997 UCSC PhD dissertation)

Kennedy, Christopher. 2001. Polar opposition and the ontology of degrees. Linguistics and Philosophy 24 (1): 33-70.

Kennedy, Christopher. 2007. Vagueness and grammar: The semantics of relative and absolute gradable adjectives. Linguistics and Philosophy 30: 1-45.

Kennedy, Christopher, and Beth Levin. 2008. Measure of change: The adjectival core of degree achievements. In Adjectives and adverbs: Syntax, semantics, and discourse, ed. Louise McNally and C. Kennedy, 156-182. Oxford: Oxford University Press.

Kennedy, Christopher, and Louise, McNally. 2005. Scale structure and the semantic typology of gradable predicates. Language 81: 345-381.

Klein, Ewan. 1991. Comparatives. In Semantik/semantics, An international handbook of contemporary research, ed. Arnim von Stechow and Dieter Wunderlich, 673-691. Berlin: de Gruyter.

Krantz, David H., R. Duncan, Luce, Patrick, Suppes, and Amos, Tversky. 1971. Foundations of measurement: additive and polynomial representations: San Diego: Academic Press.

Krasikova, Sveta. 2008. Norm-relatedness in degree constructions. In Proceedings of Sinn und Bedeutung 13, ed. Arndt Riester and Torgrim Solstad, 293-308. Stuttgart: University of Stuttgart.

Landman, Fred. 1991. Structures for semantics. Dordrecht: Kluwer.

Landman, Fred. 2005. An almost (but not quite) naive theory of measures. Manuscript and class notes, Tel Aviv University.

Lapata, Mirella, and Frank Keller. 2005. Web-based models for natural language processing. ACM Transactions on Speech and Language Processing 2 (1): 1-31.

Lehrer, Adrienne, and Keith, Lehrer. 1982. Antonymy. Linguistics and Philosophy 5: 483-501.

McConnell-Ginet, Sally. 1973. Comparative constructions in English: A syntactic and semantic analysis. $\mathrm{PhD}$ diss., University of Rochester.

Molfese, Dennis. 1985. Electrophysiological correlates of semantic features. Journal of Psycholinguistic Research 14 (3): 289-299.

Murphy, M. Lynne. 2006. Semantic, pragmatic, and lexical aspects of the measure phrase + adjective construction. In Acta lingvistica hafniensia 38, Explorations in the semantics/pragmatics interface, ed. Maj-Britt Mosegaard Hansen and Ken Turner, Copenhagen: CA Reitzels.

Nouwen, Rick. 2008. Upper-bounded no more: The exhaustive interpretation of non-strict comparison. Natural Language Semantics 16: 271-295.

Rett, Jessica. 2007. Antonymy and evaluativity. In Proceedings of semantics and linguistic theory 17. Ithaca, NY: CLC Publications.

Rullmann, Hotze. 1995. Maximality in the semantics of WH-constructions. PhD diss., University of Massachusetts, Amherst.

Sassoon, W. Galit. 2007. Vagueness, gradability and typicality, a comprehensive semantic analysis. PhD diss., Tel Aviv University.

Sassoon, W. Galit, 2009. Negative adjectives and transformation values. In Proceedings of SALT 18, ed. Tova Friedman and Satoshi Ito, 637-654. Ithaca, NY: CLC Publications.

Sassoon, W. Galit. 2010. Measurement theory in linguistics. Synthese 174 (1): 151-180. 
Schwarzschild, Roger. 2005. Measure phrases as modifiers of adjectives. Recherches Linguistiques de Vincennes 35: 207-228.

Schwarzschild, Roger, and Karina Wilkinson. 2002. Quantifiers in comparatives: A semantics of degree based on intervals. Natural Language Semantics 10: 1-41.

Seuren, Pieter. 1978. The structure and selection of positive and negative gradable adjectives. In CLS 14: Papers from the parasession on the lexicon, ed. D. Farkas, W. Jacobson and K Todrys, 336-346. Chicago: Chicago Linguistic Society.

Seuren, Pieter. 1984. The comparative revisited. Journal of Semantics 3: 109-141.

Stalnaker, Robert. 1978. Assertion. In Syntax and Semantics 9: Pragmatics, ed. Peter Cole, 315-332. San Diego: Academic Press.

Svenonious, Peter, and Christopher Kennedy. 2006. Northern Norwegian degree questions and the syntax of measurement. In Phases of interpretation, ed. M. Frascarelli, 133-161. The Hague: Mouton de Gruyter.

van Fraassen, Bas, C. 1969. Presuppositions, supervaluations and free logic. In The logical way of doing things, ed. K. Lambert, 67-91. New Haven: Yale University Press.

Veltman, Frank. 1984. Data semantics. In Truth, interpretation and information proceedings of the 3rd Amsterdam Colloquium, ed. Jeroen Groenendijk, Theo Janssen, and Martin Stokhof, 43-64. Dordrecht: Foris.

von Stechow, Arnim. 1984a. My reaction to Cresswell's, Hellan's, Hoeksema's and Seuren's comments. Journal of Semantics 3: 183-199.

von Stechow, Arnim. 1984b. Comparing semantic theories of comparison. Journal of Semantics 3: 1-77. Winter, Yoad. 2005. Cross categorial restrictions on measure phrase modification. Linguistics and Philosophy 28: 233-267. 